\title{
Origin of Thoracic Spinal Network Activity during Locomotor-Like Activity in the Neonatal Rat
}

\author{
Lauriane Beliez, Grégory Barrière, Sandrine S. Bertrand, and Jean-René Cazalets \\ Université de Bordeaux, Centre National de la Recherche Scientifique Unité Mixte de Recherche 5287, Institut de Neurosciences Cognitives et Intégratives \\ d'Aquitaine, 33076 Bordeaux, France
}

Effective quadrupedal locomotor behaviors require the coordination of many muscles in the limbs, back, neck, and tail. Because of the spinal motoneuronal somatotopic organization, motor coordination implies interactions among distant spinal networks. Here, we investigated some of the interactions between the lumbar locomotor networks that control limb movements and the thoracic networks that control the axial muscles involved in trunk movement. For this purpose, we used an in vitro isolated newborn rat spinal cord (from T2 to sacrococcygeal) preparation. Using extracellular ventral root recordings, we showed that, while the thoracic cord possesses an intrinsic rhythmogenic capacity, the lumbar circuits, if they are rhythmically active, will entrain the rhythmicity of the thoracic circuitry. However, if the lumbar circuits are rhythmically active, these latter circuits will entrain the rhythmicity of the thoracic circuitry. Blocking the synaptic transmission in some thoracic areas revealed that the lumbar locomotor network could trigger locomotor bursting in distant thoracic segments through short and long propriospinal pathways. Patch-clamp recordings revealed that $72 \%$ of the thoracic motoneurons (locomotor-driven motoneurons) expressed membrane potential oscillations and spiking activity coordinated with the locomotor activity expressed by the lumbar cord. A biphasic excitatory (glutamatergic)/inhibitory (glycinergic) synaptic drive was recorded in thoracic locomotor-driven motoneurons. Finally, we found evidence that part of this locomotor drive involved a monosynaptic component coming directly from the lumbar locomotor network. We conclude that the lumbar locomotor network plays a central role in the generation of locomotor outputs in the thoracic cord by acting at both the premotoneuronal and motoneuronal levels.

Key words: axial; coordination; in vitro; locomotion; posture; spinal cord

\section{Introduction}

Locomotor behaviors require not only the production of forces for propelling the body but also forces for maintaining balance, which is dynamically challenged during each locomotor cycle. Kinematic and electromyographic analyses of locomotor behavior in vertebrates have shown that these two requirements are achieved through an organized pattern of activation of muscles in the hindlimbs, forelimbs, and axial body segments. This implies that synergistic operations take place between the supraspinal and spinal premotoneuronal networks involved in locomotion and posture (Grillner et al., 1995; Falgairolle et al., 2006; Rossignol et al., 2006; Deliagina et al., 2008).

\footnotetext{
Received Oct. 6, 2014; revised Feb. 26, 2015; accepted March 9, 2015.

Author contributions: L.B., S.S.B., and J.-R.C. designed research; L.B. and G.B. performed research; L.B. analyzed data; L.B., G.B., S.S.B., and J.-R.C. wrote the paper.

This work was supported by the Institut pour la Recherche sur la Moelle Epinière et I'Encéphale and the Institut pour la Recherche sur la Paraplégie. We thank Laura Cardoit for her help with the immunohistological acquisition. We also thank Aslak Grinsted for the Matlab wavelet coherence package (http://noc.ac. uk/usingscience/crosswavelet-wavelet-coherence) and Philipp Berens for the circular statistics toolbox.

The authors declare no competing financial interests.

Correspondence should be addressed to Jean-René Cazalets, Université de Bordeaux Centre National de la Recherche Scientifique Unité Mixte de Recherche 5287, Institut de Neurosciences Cognitives et Intégratives d'Aquitaine, Zone nord, Bat 2, 2e étage, 146, rue Leo Saignat, 33076 Bordeaux cedex, France. E-mail: jean-rene.cazalets@u-bordeaux.fr

DOI:10.1523/JNEUROSCI.4145-14.2015

Copyright $\odot 2015$ the authors $\quad 0270-6474 / 15 / 356117-14 \$ 15.00 / 0$
}

Coordination of the trunk and limb muscles during locomotion has been described in humans (Thorstensson et al., 1982; de Sèze et al., 2008; Ceccato et al., 2009), rats (Gramsbergen et al., 1999), and cats (Carlson et al., 1979; Zomlefer et al., 1984), and evidence for a central coordination mechanism was obtained from experiments in cats (Koehler et al., 1984) and neonatal rats (Falgairolle and Cazalets, 2007). So far, however, most of our knowledge about how the motor control of the trunk is achieved during locomotion has been derived from undulatory species in which the trunk is the core of the locomotor system (Matsushima and Grillner, 1992; Roberts et al., 1998; Hagevik and McClellan, 1999; Grillner and Wallen, 2002; Cohen, 1987; for review, see Falgairolle et al., 2013). Surprisingly, little is known about the cellular mechanisms involved in the control of trunk movement during locomotion in limbed vertebrates.

Recently, using an isolated spinal cord preparation of newborn rats, we showed that the thoracic segments, in which the back-muscle motoneurons are distributed, displayed motor bursts in a 1:1 phase relationship with the lumbar motor bursts during locomotor-like activity (Falgairolle and Cazalets, 2007). A similar 1:1 relationship has also been found in intact adult rats (Gramsbergen et al., 1999), in contrast to cats (Koehler et al., 1984; Zomlefer et al., 1984) and humans (Thorstensson et al., 1982; de Sèze et al., 2008) where two back-muscle bursts per locomotor cycle occur. Interestingly, we showed that the temporal organization of these in vitro activities propagates in the caudorostral direction along the 
thoracic cord and could account for the traveling bending wave observed along the body axis of rat pups during actual locomotor movements. This indicates that intraspinal coupling mechanisms might contribute to the coordination of the body segments observed during actual locomotion. In the present work, we used the same preparation to go one step further in identifying some of the mechanisms involved in the coupling of lumbar and thoracic activities during fictive locomotion. We provide evidence that the expression of a locomotor pattern at the thoracic level depends on the activation of the lumbar locomotor network itself. At the cellular level, we identified two thoracic motoneuron subpopulations: (1) locomotor-driven motoneurons that displayed membrane potential oscillations and spiking activity in relation with the locomotor cycle and (2) nonlocomotor-driven motoneurons that have membrane potential fluctuations and spiking activity that were not correlated with locomotor-like activity. In the former group, we showed that part of the locomotor-related synaptic drive arises directly from the lumbar locomotor network, the command of which spreads throughout the thoracic segments via short and long propriospinal pathways.

\section{Materials and Methods}

Experiments were performed in vitro on isolated spinal cords from newborn Sprague Dawley rats of either sex aged from postnatal day (P) 1 to P5 ( $n=79$ preparations). All procedures were conducted in accordance with the local ethics committee of the University of Bordeaux and the European Committee Council Directive. All efforts were made to minimize animal suffering and to reduce the number of animals.

In vitro isolated spinal cord preparation. Rat pups were anesthetized using isofluorane until no reflex could be elicited in response to tail or toe pinching. Animals were decapitated, and the skin of the back was removed before the preparations were placed dorsal side up in a dissecting chamber. A laminectomy was performed to expose the spinal cord, which was carefully dissected using fine forceps and microscissors under a binocular magnifier. Dissections and recording procedures were performed under continuous superperfusion of artificial CSF (aCSF) equilibrated with $95 \% \mathrm{O}_{2}-5 \% \mathrm{CO}_{2}, \mathrm{pH} 7.4$, at room temperature $\left(24-26^{\circ} \mathrm{C}\right)$ and contained the following (in mM): $130 \mathrm{NaCl}, 3 \mathrm{KCl}, 2.5 \mathrm{CaCl}_{2}, 1.3 \mathrm{MgSO}_{4}$, $0.58 \mathrm{NaH}_{2} \mathrm{PO}_{4}, 25 \mathrm{NaHCO}_{3}$, and 10 glucose. Spinal cords were sectioned at the $\mathrm{T} 2$ level at the beginning of the experiment. In some experiments, the spinal cord was artificially partitioned using Vaseline walls as previously described (Cazalets et al., 1995) to restrict the bath application of pharmacological agents to specific spinal segments. The watertightness of the barriers was systematically checked at the end of the experiment by observing the movements of methylene blue added to the bathing medium on one side of the Vaseline walls.

Electrophysiological recordings and analyses. To readily access the axial muscle motoneurons, we developed a specific preparation in which a transverse section of the spinal cord at a given thoracic segment was cut using fine scissors (MC-26B, Moria). To set the section upright and facilitate the positioning of a glass microelectrode, the cut surface of the spinal cord was positioned on a Sylgard block (see Fig. 4B). From the 59 motoneurons used in the present study, 32 were patch-clamp recorded in whole-cell configurations and 27 were recorded using intracellular sharp microelectrodes with a Multiclamp 700B amplifier (Molecular Devices). Motoneurons were identified by the presence of antidromic action potentials elicited by segmental ventral root stimulations. Only those motoneurons with a resting membrane potential $<-50 \mathrm{mV}$ and a spike amplitude of $\geq 50 \mathrm{mV}$ were considered. Patch-clamp glass microelectrodes (4-7 M $\Omega$ ) were filled with the following solution (in $\mathrm{mM}$ ): 120 K-gluconate, $20 \mathrm{KCl}, 0.1 \mathrm{MgCl}_{2}, 1$ EGTA, $10 \mathrm{HEPES}, 0.1 \mathrm{CaCl}_{2}, 0.1 \mathrm{GTP}$, 0.2 cAMP, 0.1 leupeptin, 77 D-mannitol, $3 \mathrm{Na}_{2}-\mathrm{ATP}, \mathrm{pH}$ 7.3. Sharp glass microelectrodes $(70 \mathrm{M} \Omega$ ) were filled with $2 \mathrm{M} \mathrm{K}$-acetate. Extracellular motor activities were recorded from various spinal cord ventral roots. For long ventral roots at the lumbar level, Vaseline-insulated stainless steel pin electrodes were used. For the short thoracic ventral roots, glass suction electrodes were used. Extracellular activities were amplified using custom-made amplifiers. Electrophysiological recordings were digitized using an analog-to-digital interface (Heka) driven by the Axograph software (Axograph). Extracellular raw signals were high-pass filtered (50 $\mathrm{Hz}$ ), rectified, and integrated before analysis. Locomotor parameters were computed using custom-made routines written in Matlab (Mathworks). The mean cycles were computed using one L2 ventral root as the reference because it invariably exhibited the best signal-to-noise ratio (Fig. 1). Wavelet transform analyses (Mor and Lev-Tov, 2007) were performed using the Matlab wavelet coherence package provided by Aslak Grinsted (http://noc.ac.uk/using-science/crosswavelet-wavelet-coherence). This methodology is more accurate than conventional manual or semiautomated burst detection methods, especially with low signal-to-noise ratio recordings (Mor and Lev-Tov, 2007). Moreover, using this method allows access to the evolution of a signal's frequency content over time. Of particular interest is the possibility of extracting the common power, correlation, and phase relationship between two simultaneously acquired signals of the cross wavelet transform and wavelet coherence (Torrence and Compo, 1998; Grinsted et al., 2004). A detailed explanation of the wavelet-based methodology used in the present work had been previously presented by Mor and Lev-Tov (2007) (Torrence and Compo, 1998; Grinsted et al., 2004). Each pretreated signal was decomposed in the frequency domain over time using a continuous wavelet transform (Morlet wavelet, 10 octaves per scale). Cross-wavelet and wavelet coherence algorithms were applied to paired, pretreated signals to highlight the common high-power frequencies (color coded) and significant correlations (color coded) between each frequency component between signals over time. The changes in rhythmic activity frequencies and the coherence and phase relationships between the signals were then extracted from regions of interest that were defined from mixed cross-coherence maps in which the results of the cross wavelet and wavelet coherence were combined (Mor and Lev-Tov, 2007). For this purpose, each power value obtained in the time/frequency domain from the cross-wavelet transform was weighted by the corresponding value of coherence (ranging from 0 to 1 ) obtained from the wavelet coherence. This allows highlighting of the time/frequency regions in which the two signals not only share common high-power values but are also highly coherent.

Pharmacology. Episodes of locomotor-like activities were elicited by the exogenous application of a mixture of $15 \mu \mathrm{M} N$-methyl-D,L-aspartate (NMA) and $15 \mu \mathrm{M}$ serotonin (5-HT; (Cazalets et al., 1992). All drugs were from Sigma-Aldrich. Glycinergic receptors were blocked using strychnine and glutamatergic NMDA. Non-NMDA receptors were blocked using (2R)-amino-5-phophonovaleric acid (APV) and 6,7dinitroquinoxaline-2,3-dione (DNQX), respectively. We also occasionally replaced the normal saline with either a modified aCSF that contains low-calcium/high-magnesium concentrations $\left(0.1 \mathrm{~mm} \mathrm{CaCl}_{2}, 5 \mathrm{~mm}\right.$ $\mathrm{MgCl}_{2}$ ) to locally block the chemical synaptic transmission (Richards and Sercombe, 1970; Morin and Viala, 2002) or an isotonic sucrose solution (339 mm in distilled water, adjusted to $\mathrm{pH} 7.4$ ) to reversibly block neuronal activity in some segments (Sqalli-Houssaini et al., 1993). A highcation-containing aCSF $\left(7.5 \mathrm{~mm} \mathrm{CaCl}_{2}\right.$ and $\left.8 \mathrm{~mm} \mathrm{MgSO}_{4}\right)$ was also used to decrease the polysynaptic transmission in spinal segments (Berry and Pentreath, 1976; Jahr and Yoshioka, 1986; Cazalets et al., 1995).

Immunochemistry. Spinal cords were fixed in $4 \%$ paraformaldehyde in PBS overnight at $4^{\circ} \mathrm{C}$, cryoprotected in $20 \%$ sucrose, embedded in OCT Tissue-Tek, frozen, and cut transversely on a cryostat $(30 \mu \mathrm{M})$. The slices were mounted on slides and processed for choline acetyl transferase (ChAT) immunodetection using a goat anti-ChAT antibody (1:100; Millipore) revealed with an Alexa Fluor 488 donkey anti-goat secondary antibody (1:500; Tartas et al., 2010). Images of ChAT-immunopositive cells were acquired using a Nikon AZ100M microscope.

Retrograde labeling of back-muscle motoneurons. Neonatal rats (P1-P3) were anesthetized with isofluorane until the loss of reflexive movement in response to tail or toe pinching and were then placed on a cold pad. Small incisions were made in the skin to expose the back muscles. Crystals of cholera toxin-B subunit Alexa Fluor 594 conjugate (Invitrogen), a retrograde tracer, were carefully inserted using insect pins into the right back muscles at different levels along the axis. The skin was bonded with surgical glue and pups were progressively warmed up and checked during recovery from the anesthesia before being returned to their mother. One day after tracer injection, the pups were anesthetized using isoflurane and their spinal cords were dissected out and postfixed in $4 \%$ paraformalde- 
A

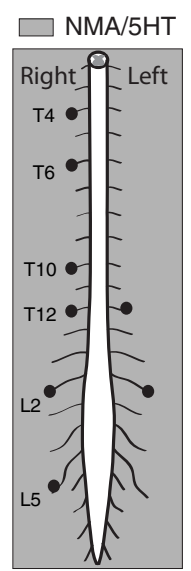

r T4

r T6

r T10

I T12

r T12

I L2

r L2

r L5

L5

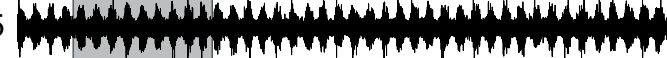

$20 \mathrm{~s}$

C

Cross wavelet transform

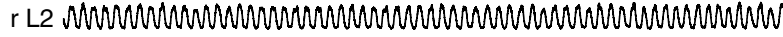

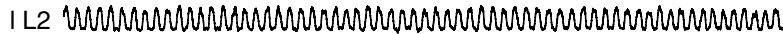

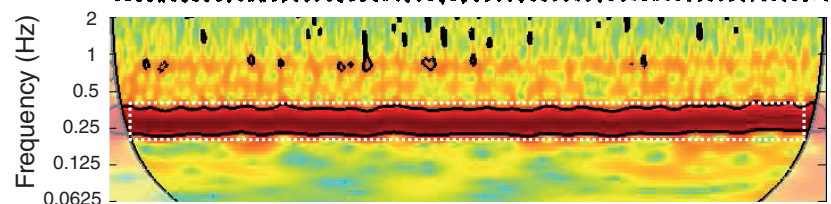

Coherence

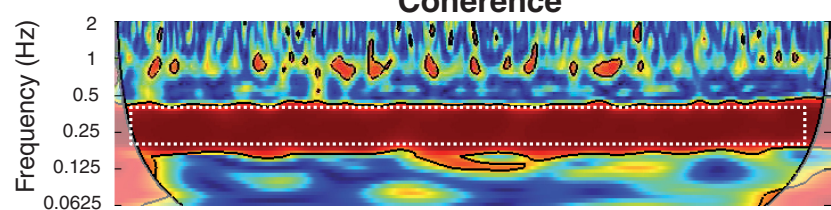

Mixed cross-coherence map

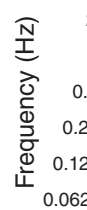

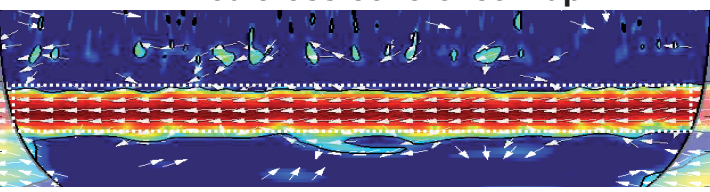

$1+2=$

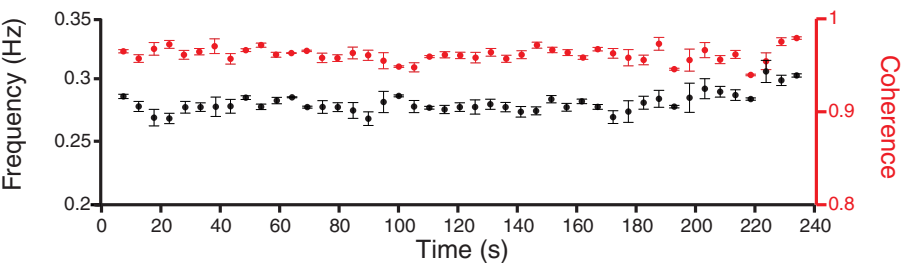

B
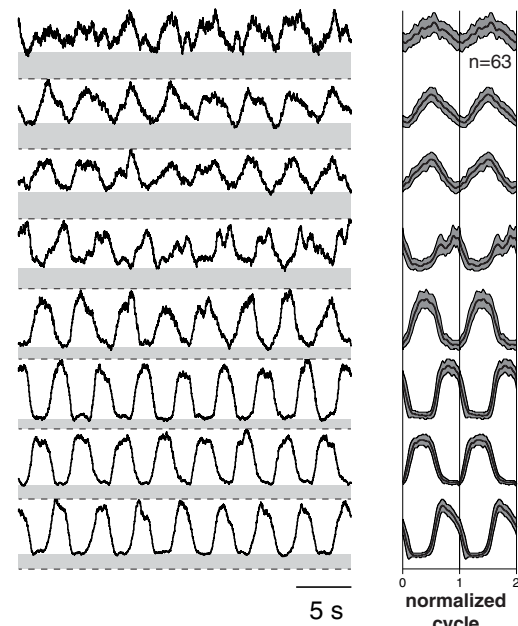

D

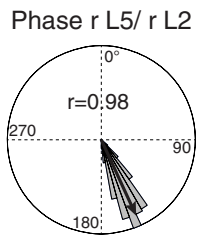

Phase r T12/ r L2

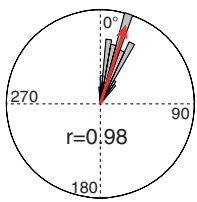

Phase rT10/r L2

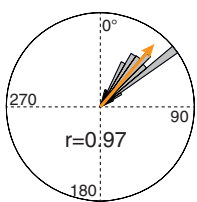

Phase r T4/ r L2

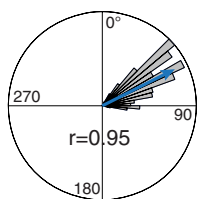

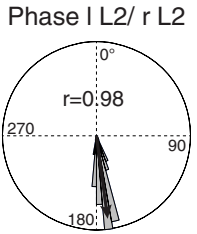

Phase I T12/ r L2

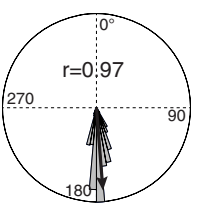

Phase r T6/ r L2

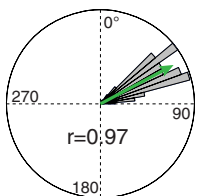

L2

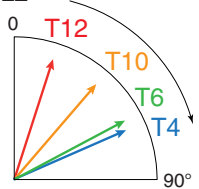

Figure 1. Thoracolumbar bursting coordination during fictive locomotion. $A$, Schematic diagram of the experimental procedure (left). Simultaneous recordings from lumbar and thoracic ventral roots during an episode of locomotor-like activity induced by NMA (15 $\mu \mathrm{m}$ ) and 5-HT (15 $\mu \mathrm{m}$; right). $\boldsymbol{B}$, High-pass filtered, rectified, and smoothed traces (left) taken from the sequence presented in $\boldsymbol{A}$ (gray area). The right panel illustrates the mean normalized cycle repeated two times ( $n=63$ cycles, right $L 2$ taken as reference). $\boldsymbol{C}$, Example of the wavelet analysis performed between pairs of recordings. Cross wavelet transform (top) and wavelet coherence between bilateral L2 activities revealed the common high-power frequencies and correlation between signals over time, respectively. The power and coherence of the frequencies between traces are color coded with warm and cool colors to indicate high and low values, respectively. Black contours delimit areas within the $5 \%$ significance level. Regions of interest (white dashed rectangles) were defined from the map obtained by mixing the results of the cross-wavelet and wavelet coherence (bottom map). White arrows indicate the phase relationship between each significant frequency components (the left direction indicates an out-of-phase relationship). The bottom graphs illustrate the evolution of the frequency (black markers) and coherence (red markers) over time within the regions of interest. Each marker represents the mean values obtained using bins of 1 s. $D$, Polar plot representations of the phase relationships between the bursting activities recorded from various ventral roots and the right $L 2$. The direction and length of the red arrows indicate the mean phase value and the $r$ value, respectively. The distributions of raw values are also provided as histograms (using bins of $5^{\circ}$ ). r, Right; I, left; T, thoracic; L, lumbar.

hyde in $0.2 \mathrm{~m}$ phosphate buffer. After dehydration, the spinal cord was cut and prepared for ChAT immunochemistry.

Statistical analysis. Statistical analyses were performed on the raw data with nonparametric $t$ tests using Prism software (Graphpad). The Wilcoxon matched-pair test was used to compare two series of data. Oneway ANOVA was performed to test $>2$ groups. The level of significance was set at $p<0.05$. All data are expressed as the mean \pm SEM in the text and in the figures. The asterisks in the figures indicate positive significance levels, and the numbers in or above the histogram bars refer to the number of neurons tested. Circular statistics were performed using the circular statistic toolbox in Matlab (Berens, 2009) and Oriana (Kovach Computing Services). 


\section{Results \\ Coordination of thoracolumbar activity patterns during fictive locomotion}

In this first series of experiments, locomotor-like activity was elicited from isolated spinal cord preparations using exogenous applications of NMA $(15 \mu \mathrm{M})$ and 5-HT $(15 \mu \mathrm{M})$. When bathapplied to the whole thoracolumbosacral spinal cord, this mixture elicited sustained episodes of stable locomotor-like activity at the lumbar level in all of the preparations tested $(n=79$; mean period, $3.32 \pm 0.09 \mathrm{~s}$ ), characterized by a bilateral alternation of segmental motor bursts and an homolateral alternation of flexorlike and extensor-like motor bursts recorded from the L2 and L5 ventral roots, respectively. Under this experimental condition, thoracic ventral roots showed rhythmical bursting activities in 63 of 79 preparations (79\%; Fig. $1 A$ ). In the remaining 16 of 79 preparations, the locomotor activity recorded at the lumbar level did not spread up to the thoracic segments, where only a tonic activity was observed (data not shown). In the 63 preparations from which thoracic motor bursts were evoked, we computed the level of tonic activity from the baseline, which is shown by the gray area below each rectified and smoothed recording from the ventral roots in the left panel of Figure $1 B$. The ratio between the amplitudes of the burst and tonic components of the recorded activities was smaller in the thoracic segments than in the lumbar segments. On average, the mean ratio obtained from the L2 ventral roots in all experiments $(n=63$ preparations, $1.75 \pm 0.08)$ was significantly greater than the mean ratio obtained from pooled thoracic recordings $(1.09 \pm 0.01, p<0.0001$, MannWhitney test). A serotonergic activation of sympathetic related neurons in the intermediolateral cell column at the thoracic level may have contributed to the decreased ratio at this level (Pierce et al., 2010). In this context, we decided to use a wavelet transformbased method to investigate the relationships of thoracic and lumbar activities (see Materials and Methods; Mor and Lev-Tov, 2007). This is illustrated in Figure $1 C$ (top), in which the timefrequency map in the range of $0.0625-2 \mathrm{~Hz}$ was obtained by the cross-wavelet transform of the bilateral L2 ventral roots recordings presented in Figure 1A. From this time-frequency map, the power of each frequency is coded using cold (low power) and hot (high power) colors, and we can see that both L2 roots share a high power in a frequency band ranging from 0.25 to $0.4 \mathrm{~Hz}$. This band was included in an area within which both signals were highly coherent, as shown by the coherence spectrum (Fig. 1C, middle). For convenience, the cross-wavelet and coherence spectrums were combined in a mixed cross-coherence map (see Material and Methods; Mor and Lev-Tov, 2007) to highlight the regions in which both signals share high-power frequencies that are also highly coherent (Fig. 1C, bottom map). From this map, we defined a region of interest (dashed white rectangle) from which the locomotor frequency $(0.28 \pm 0.01 \mathrm{~Hz})$ and coherence values $(0.96 \pm 0.01)$ were extracted (from the cross-wavelet and coherence spectrum, respectively) and plotted over time (Fig. 1C, bottom plot). Finally, from the cross-wavelet transform, we also extracted the evolution of the phase relationship between both L2 roots within the frequency range of interest. The evolution of the phase relationship over time between both L2 roots is indicated by the white arrows on the cross-coherence map. Arrows pointing to the left indicate in phase relationships while arrows pointing to the right indicate out-of-phase relationships. In the region of interest illustrated in the cross-coherence map of Figure $1 B$, all arrows point to the left, indicating that the activities recorded from the two L2 roots are in phase opposition $\left(172.2 \pm 8.6^{\circ}\right)$, as expected during locomotor-like activity in this preparation.

The polar plots in Figure $1 D$ show the phase relationships between all recorded ventral roots and the right $\mathrm{L} 2$, which was used as the reference. The polar plots on the top of Figure $1 D$ illustrate the typical organization of rhythmical burst activity at the lumbar level during an episode of fictive locomotion. This activity is characterized by an alternation of homolateral extensor-like and flexor-like activities $\left(\mathrm{rL} 5 / \mathrm{rL} 2,155.3 \pm 9.8^{\circ}\right)$ together with a bilateral alternation of activity recorded at each segmental level ( $\left.1 \mathrm{~L} 2 / \mathrm{rL} 2,172.3 \pm 8.6^{\circ}\right)$. These plots indicate that the bursting activity recorded at the thoracic level were phase-locked to the lumbar locomotor activity. As previously reported, there was a progressive caudorostral propagation of motor bursts along the thoracic segments (Falgairolle and Cazalets, 2007; Beliez et al., 2014). Indeed, computing the phase relationships between the bursting activity recorded from the various ventral roots and the right L2 showed that the phase value increased from the caudal to rostral ipsilateral thoracic segments $\left(\right.$ rT12/rL2, $17.8 \pm 10.2^{\circ} ;$ rT10/rL2, $40.7 \pm 11.7^{\circ} ;$ rT6/rL2, $62.0 \pm$ $\left.12.5^{\circ} ; \mathrm{rT} 4 / \mathrm{rL} 2,63.2 \pm 16.8^{\circ}\right)$. In addition to the segmental alternating activity $\left(\mathrm{lL} 2 / \mathrm{rL} 2,172.3 \pm 8.6^{\circ}\right)$ and between the homolateral extensor-like and flexor-like activities (rL5/rL2, $\left.155.3 \pm 9.8^{\circ}\right)$ during fictive locomotion, segmental thoracic bursts also alternated, as shown by the opposite direction of the mean vector computed from bursting activities of the left T12 and right T12 as well as those from the right L2 (1T12/rL2, $175.5 \pm 11.8^{\circ}$; rT12/rL2, $\left.17.8 \pm 10.2^{\circ}\right)$.

\section{Conditional rhythmogenic capacity of the isolated thoracic cord}

To investigate the rhythmogenic capacity of the thoracic segments, the spinal cord was artificially partitioned at the T12/T13 level ( $n=28$ preparations) to restrict the bath application of NMA/5-HT to the thoracic or lumbosacral segments. Under control conditions in which NMA/5HT was bath-applied to both compartments, the rhythmic activity in the two regions was synchronized (Fig. 2A1). In these preparations, restricting the NMA/ 5-HT bath application to the lumbosacral segments triggered locomotor-like activity at the lumbar level, whereas the thoracic segments remained silent (Fig. 2A2). In this later case, however, the lumbar locomotor period $(2.68 \pm 0.14 \mathrm{~s}, n=28$ preparations) was significantly decreased compared with the control $(3.16 \pm 0.14 \mathrm{~s}, p<0.05$, paired $t$ test), indicating that the thoracic segments contributed to regulating the cycle duration of the lumbar locomotor network (Fig. 2B). In all cases, applying NMA/ 5 -HT only to the thoracic segments only triggered a tonic activity at the thoracic level and failed to initiate any rhythmical activity (Fig. 2A3).

In a previous study, we showed that the thoracic cord was able to generate slow nonlocomotor rhythmic bursting when isolated from the lumbar enlargement by a transection of the cord at the T12/T13 level (in 75\% of cases with bath application of NMA plus either 5-HT or DA; Falgairolle and Cazalets, 2007). In the present work, following the same transection, bath application of NMA/5-HT elicited rhythmic activity in 6 of 18 preparations, as illustrated in Figure $2 C 1, C 2$. Under the control condition, in which NMA/5-HT was applied to the whole spinal cord before transection, NMA/5-HT triggered coordinated locomotor bursting activities between the thoracic and lumbar cord (Fig. 2C1). Following transection, a new application of NMA/5-HT elicited at the thoracic level a slow rhythmic bursting activity that was no longer related to the lumbar locomotor-like activity (Fig. 2C2). The thoracic and lumbar cycle periods were significantly increased $(7.87 \pm 0.87 \mathrm{~s}, n=62$ cycles $)$ and decreased ( $2.6 \pm 0.01 \mathrm{~s}, n=202$ cycles), respectively, compared 
A1

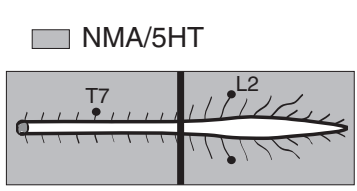

I T7

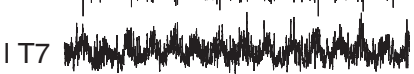

I 2 HHAHHWHWH

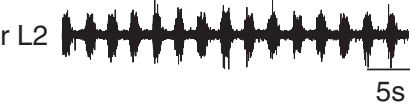

C1

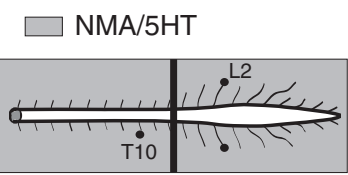

r T10
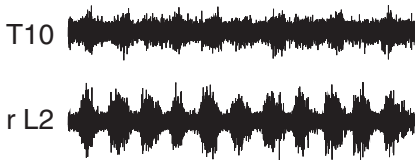

I L2

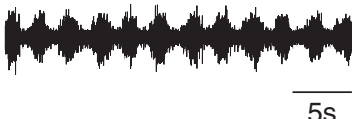

A2
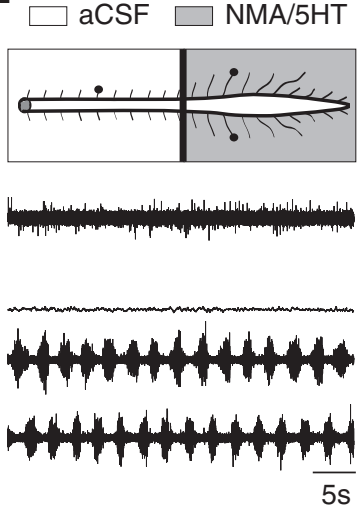

C2
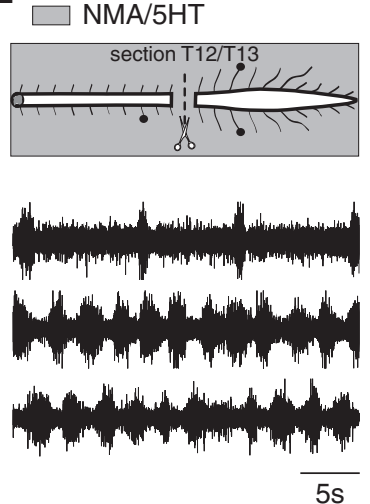

A3
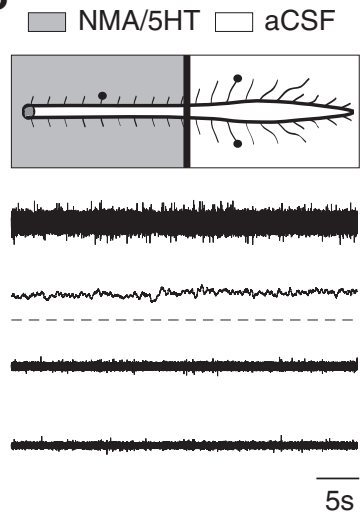

5s

D1

NMA/5HT

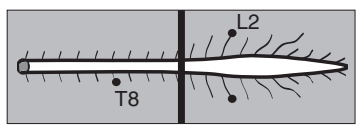

r T8

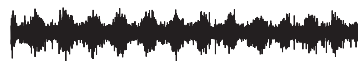

r L2

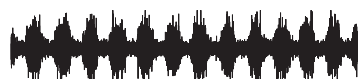

I L2

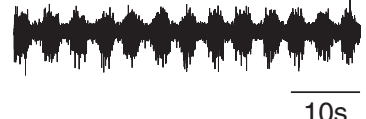

B

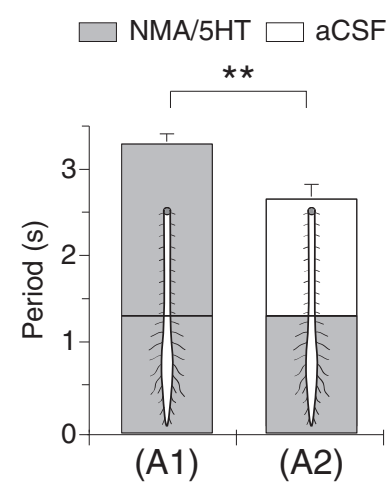

D2
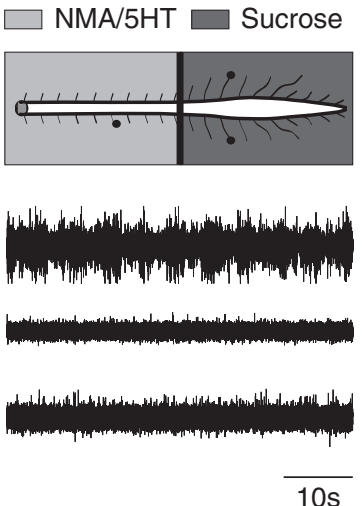

Figure 2. Conditional rhythmogenic capabilities of thoracic spinal segments. $\boldsymbol{A}$, Raw or integrated $(\equiv)$ extracellular activities were recorded in whole spinal cords (A1) or lumbar (A2) or thoracic (A3) segments treated with NMA $(15 \mu \mathrm{M})$ and $5-\mathrm{HT}(15 \mu \mathrm{M})$, coordinating with the rhythmic motor bursts recorded from the left thoracic T7 and left and right lumbar L2 ventral roots. $\boldsymbol{B}$, Plot of the locomotor period as a function of the experimental condition (NMA/5-HT applied to the whole preparation or to the lumbar part, $n=28$ preparations). C, D, Extracellular activities recorded from T10 or T8 and bilateral L2 ventral roots during the application of NMA/5-HT to the whole spinal cord under control conditions $(\mathbf{C 1}, \mathbf{D 1})$, after T12/T13 sectioning (C2) or in the presence of a sucrose block on the lumbar segments (D2). r, Right; I, left; T, thoracic; L, lumbar.

with the control cycle period measured before transection $(3.00 \pm$ $0.09 \mathrm{~s}, n=51$ cycles, $p<0.05$, Mann-Whitney test). Under the same conditions, however, 12 of 18 preparations only expressed a tonic activity at the thoracic level after transection. In these latter preparations, however, increasing the excitability of the thoracic networks by adding a GABAergic antagonist (gabazine, $1 \mu \mathrm{M}$ ) to the bathing saline containing NMA/5-HT triggered a slow rhythmic motor activity ( $n=9$ preparations, $7.82 \pm 0.76 \mathrm{~s}$, data not shown).

Because the use of transection in this preparation may haveled us to underestimate the endogenous rhythmic capacities of the restricted spinal cord segments (Juvin et al., 2005), we also bathapplied NMA/5-HT to the thoracic cord after blocking neuronal activity by superfusing an isotonic sucrose solution onto the lumbosacral segments (see Materials and Methods). Under these conditions, we observed the same slow pattern of thoracic bursting that was observed after transection (Fig. 2, compare D1, D2), with a significant increase of the bursting period ( $n=7$ preparations, $8.23 \pm 1.06 \mathrm{~s}$ ) compared with the control locomotor period $(3.57 \pm 0.37 \mathrm{~s})$.

The coordinating mechanisms between the thoracic and lumbar networks may involve long ascending propriospinal pathways and/or segmentally relayed ascending inputs that propagate from one thoracic segment to another. To test these hypotheses, the spinal cord was artificially divided into three compartments (T3-T5, T6-T11, T12-cauda equina) using Vaseline walls. In all six preparations tested, applying NMA/5-HT simultaneously in the three compartments triggered coordinated locomotor bursts along the spinal cord (Fig. $3 A$ ). A blockade of synaptic activity by local application of aCSF containing low $\mathrm{Ca}^{2+} /$ high $\mathrm{Mg}^{2+}$ over the T6-T11 segments did not prevent the expression of locomotor bursting in the upper thoracic segments, which remained locked to the lumbar activity (Fig. $3 B$ ). However, this synaptic blockade of interposed thoracic relays elicited a significant phase shift ( $p<0.005$, Watson $\mathrm{U}^{2}$ test) in the upper thoracic motor bursting at the T5 (mean phase value: control, $54 \pm 28.8^{\circ}$; low $\mathrm{Ca}^{2+} /$ high $\mathrm{Mg}^{2+}, 122.4 \pm 39.6^{\circ}$ ) and $\mathrm{T} 3$ (mean phase value: control, $79.2 \pm 43.2^{\circ}$; low $\mathrm{Ca}^{2+} /$ high $\mathrm{Mg}^{2+}, 140.4 \pm 39.6^{\circ}$; Fig. $3 C)$ levels. The motor burst phase shift was observed in all six preparations in which the experiment was performed (mean phase value at T5: control, $93.6 \pm 14.4^{\circ}$; low $\mathrm{Ca}^{2+} / \mathrm{high}_{\mathrm{Mg}}{ }^{2+}$, $111.6 \pm 14.4^{\circ}, p<0.005$, Watson $\mathrm{U}^{2}$ test). This indicates that both the long ascending propriospinal fibers and segmentally relayed ascending information contributed to the coordination of thoracic and lumbar bursting activities.

\section{Localization of thoracic motoneurons innervating the} paraspinal back muscles

In a previous study, we showed that the motoneurons that innervate the back muscles (longissimus and multifidus dorsali muscles) were organized into columns along the thoracolumbar spinal cord (Falgairolle and Cazalets, 2007), but their location in the transversal plane was not defined. Before achieving intracel- 


\section{A}

$\mathrm{NMA} / 5 \mathrm{HT}$

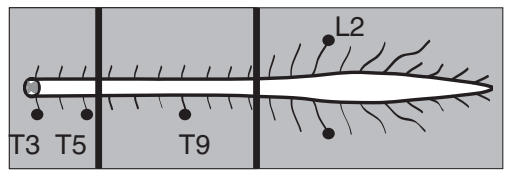

r T3

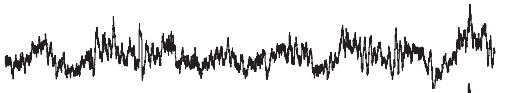

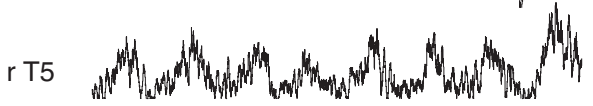

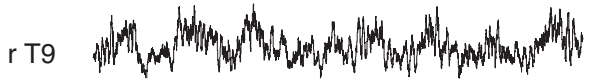

r L2

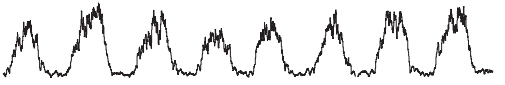

I L2

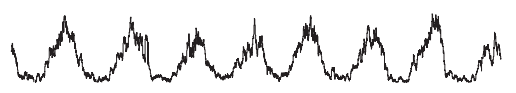

3s

B

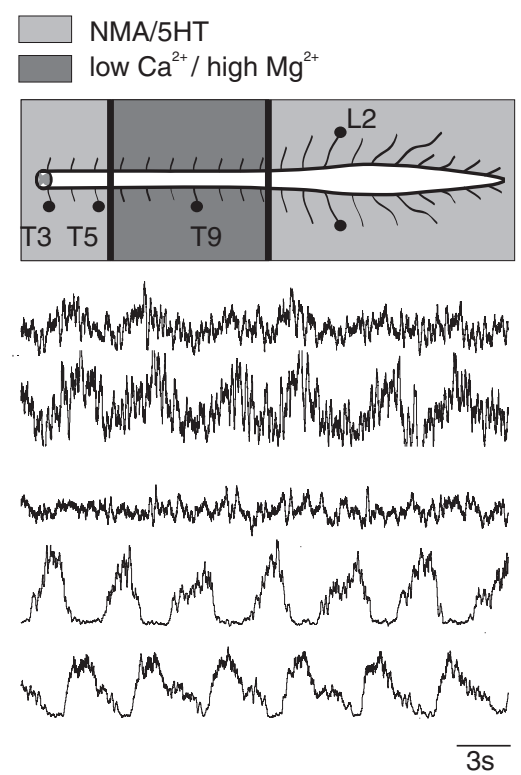

C

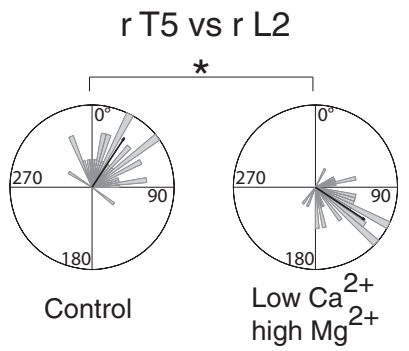

rT3 vs r L2

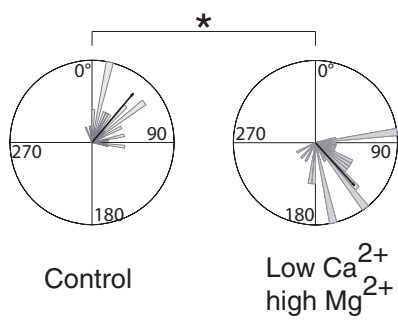

Figure 3. Evidence of long ascending pathways between lumbar and thoracic networks. $A$, Coordinated locomotor-like activities recorded at different thoracolumbar levels triggered by bath application of NMA/5-HT to the whole spinal cord preparation. $\boldsymbol{B}$, Effects of the synaptic transmission blockade on the NMA/5-HT-induced locomotor activity in T6-T12 segments treated with an aCSF solution containing low $\mathrm{Ca}^{2+} / \mathrm{high} \mathrm{Mg}^{2+}$. Note the absence of bursting activity on T9. C, Polar plots of the phase relationships between $\mathrm{T3}$ (bottom) or T5 (top) and right L2 locomotor bursts

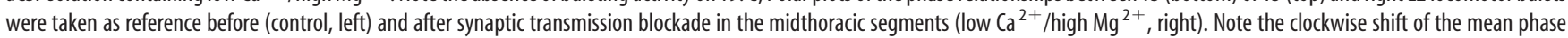
observed at both thoracic levels in the presence of the low- $\mathrm{Ca}^{2+} /$ high- $\mathrm{Mg}^{2+}$ solution. r, Right; I, left; $\mathrm{T}$, thoracic; L, lumbar.

lular recordings from axial thoracic motoneurons, the precise determination of their location in the spinal cord was a prerequisite. ChAT immunolabeling revealed the two main motoneuronal populations in lamina IX along the thoracic cord (Fig. 4A1). To locate the back-muscle motoneurons, Alexa Fluor 594conjugated cholera toxin-B subunit (CTB-AF 594) crystals were inserted into the longissimus and multifidus dorsali muscles on one side ( $n=3$ preparations). In agreement with the literature (Smith and Hollyday, 1983), retrogradely labeled motoneuron somata from these muscles (Fig. 4A2) were located exclusively in the ventromedian motoneuronal population (Fig. 4A3).

Locomotor and nonlocomotor-driven thoracic motoneurons Intracellular patch-clamp recordings from motoneurons were performed along the thoracic cord (from T3 to T12) to investigate the activity of thoracic axial motoneurons during episodes of locomotor-like activity. For this purpose, we used a spinal cord preparation that was transversally cut at various recording levels so that we could visually target the ventromedially located motoneurons (see Materials and Methods; Fig. 4B). Our results are based on the recordings made from 59 antidromically identified thoracic motoneurons (Fig. $4 B$, left trace) that could be recorded for $>1 \mathrm{~h}$.

During the bath application of NMA/5-HT to the thoracolumbosacral spinal cord preparations, we found that 25 of 33 of the recorded motoneurons fired action potential bursts in coordination with the locomotor activity recorded from the lumbar ventral roots. Figure $4 C$ provides a representative example of the changes that occurred in a thoracic locomotor-driven motoneuron when the locomotor networks were activated. During the first few minutes of NMA/5-HT application, a tonic activity was observed in the ventral roots before a stable locomotor activity took place at the lumbar level. Concomitantly, the thoracic motoneuron membrane potential underwent a gradual depolariza- tion associated with an increase of synaptic inputs (data not shown; see Fig. 6A). Thereafter, motoneurons started to fire action potentials during the depolarization phase of the membrane potential oscillations (Fig. 4C, middle). Plots of the spike distributions during the various motor cycle phases (arbitrarily divided into 10 bins; Fig. 4C, right) showed a clear locomotorrelated modulation. In contrast, in the remaining 8 of 33 thoracic nonlocomotor-driven motoneurons, spiking activity was uniformly distributed and was not related to any particular phase of the motor cycle, although a locomotor-related activity was observable in the extracellular recording from the corresponding thoracic ventral root (Fig. 4D). Furthermore, the two types of motoneurons could be recorded at the same segmental levels in the same preparations ( $n=5$ preparations).

To determine whether the absence of bursting activity observed in the thoracic ventral roots after the restricted pharmacological activation of lumbosacral segments was due to subthreshold activation of the thoracic motoneurons, we performed intracellular recordings in the thoracic motoneurons (Fig. 5). When a NMA/5-HT-supplemented aCSF solution was specifically superfused onto the lumbosacral cord (Fig. 5A1,B1), no rhythmical activity could be extracellularly recorded from the thoracic ventral roots, but 13 motoneurons of the 25 tested presented membrane potential oscillations that were rhythmically synchronized with the locomotor-like activity recorded at the lumbar level. To ascertain the presence or absence of coupling between the extracellular activity recorded from the lumbar area and the intracellular activity of recorded thoracic motoneurons, the locomotor sequences obtained under this experimental condition were analyzed using wavelet transformation methodology. The membrane potential oscillations recorded from one locomotor-driven motoneuron located in the left T7 segment during lumbar fictive locomotion is illustrated in Figure 5A2. The mixed cross-coherence map presented in Figure $5 A 3$ shows that 
A1

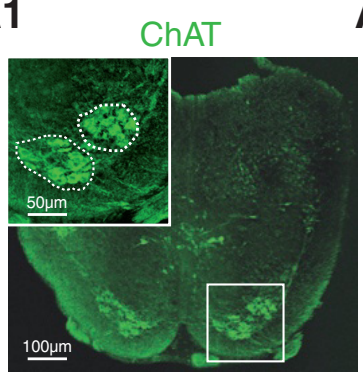

A2

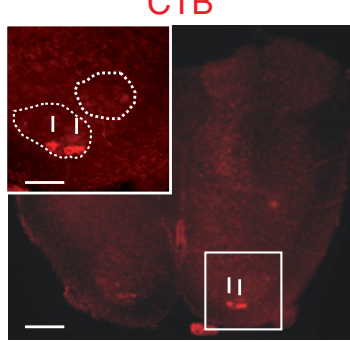

A3

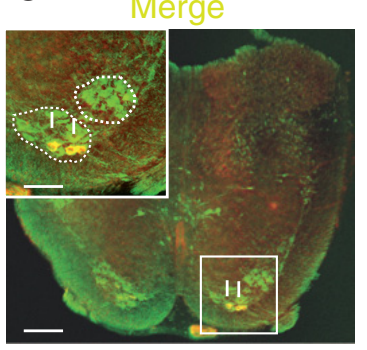

B

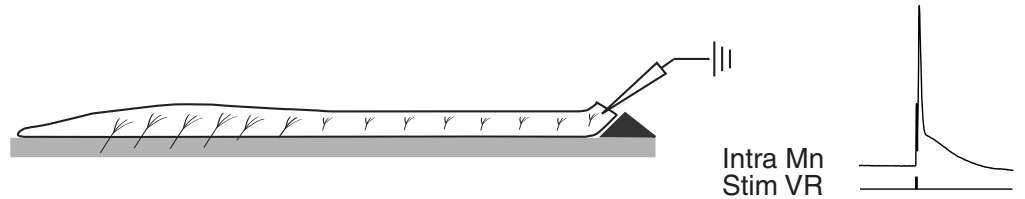

C $\square \mathrm{NMA} / 5 \mathrm{HT}$
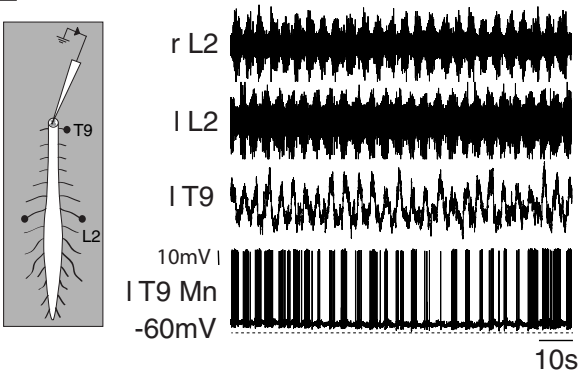

Thoracic locomotor-driven $\mathrm{Mn}$

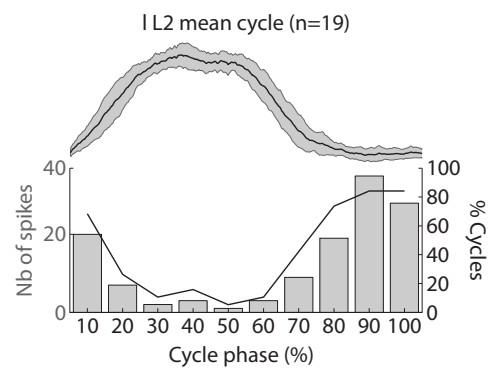

D

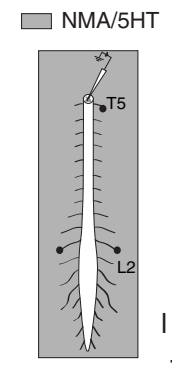

Thoracic non locomotor-driven $\mathrm{Mn}$
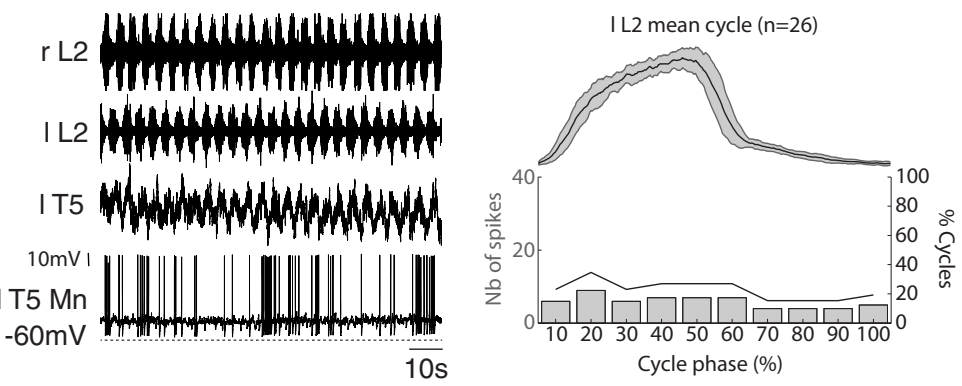

Figure 4. Localization and intracellular characterization of thoracic motoneurons. $A$, Localization of motoneurons innervating the axial back muscles in the T12 segment. $\boldsymbol{A 1}$, Photomicrographs of ChAT immunoreactivity in T12 showing the ventromedial and lateral motoneuronal populations in lamina IX. The upper left inset shows details at higher magnification. $\mathbf{A 2}$, Motoneurons were retrogradely labeled with a cholera toxin-B subunit Alexa Fluor 488 conjugate (CTB) injected into the back muscles. A3, The merge panel shows that the motoneurons of the back muscles are located in the ventral part of the ventromedial motoneuronal population. The arrows in $\mathbf{A} \mathbf{2}$ and $\mathbf{A} \mathbf{3}$ point to double-labeled motoneurons. $\boldsymbol{B}$, Schematic of the experimental procedure (left). The spinal cord was transected at a given thoracic segment and placed on a Sylgard support to allow access to the motoneurons with intracellular electrodes. Motoneurons were identified by the presence of an antidromic action potential recorded in response to stimulations of the corresponding ventral root (right). C, Diagrams of the experimental procedure (left). Extracellular recordings of the left and right $\mathrm{L} 2$ ventral roots during an episode of NMA $/ 5-\mathrm{HT}$-induced fictive locomotion together with theintracellular recording of a $\mathrm{T} 9$ motoneuron that rhythmically emitted a burst of action potentials in phase with the locomotor cycle (a locomotor driven motoneuron). Bar histograms in the right panel represents the number of spikes emitted during the locomotor cycle (normalized and averaged from the left L 2 bursting activity and arbitrarily splitinto 10 subphases, top trace). The thick black line in the graph indicates for each locomotor cycle subphase the percentage of cycles (right ordinate) during which the motoneurons fired action potentials. D, Same as $\mathbf{C}$ but for a T5 motoneuron that exhibited action potentials independent from the locomotor activity (a nonlocomotor-driven motoneuron). r, Right; l, left; T, thoracic; L, lumbar; Stim VR, ventral root stimulation.

the bilateral L2 bursting activities (Fig. 5A3, top) were significantly correlated in a frequency band (white rectangle) corresponding to a mean cycle frequency of $0.4 \pm 0.02 \mathrm{~Hz}$. As expected, bilateral L2 bursting activities in this frequency band

were alternating (mean phase left/right L2: $184.9 \pm 10.9^{\circ}$, not illustrated). Of particular interest was the observation that in the same frequency band, the motoneuron expressed membrane potential oscillations that were also significantly correlated to the lumbar activity (Fig. $5 A 3$, bottom) with a mean phase value of $194.2 \pm 12.6^{\circ}$ between the left motoneuron and the right L2. In contrast, the remaining 12 of 25 motoneurons tested under the same experimental conditions did not express any oscillations in membrane potential, as illustrated for a $\mathrm{T} 5 \mathrm{mo}-$ toneuron in Figure 5B2. In this case, wavelet analysis of the sequence revealed that during the lumbar locomotor activity, during which bilateral L2 activities alternated (mean phase: $\left.183.6 \pm 10.3^{\circ}\right)$ at a mean frequency of $0.21 \pm 0.01 \mathrm{~Hz}$ (Fig. $5 B 3$, top), the membrane potential fluctuations were not significantly correlated to the lumbar activity (Fig. 5B3, bottom).

The nature of the motoneuron, i.e., locomotor-driven and nonlocomotordriven, was not affected by whether NMA/ 5-HT was applied over the thoracolumbar segments or at the lumbar level alone $(n=$ 20 motoneurons). This indicated the coexistence of two functionally different populations of thoracic motoneurons. From the 59 motoneurons recorded in one or both experimental conditions, 38 (64\%) were locomotor-driven motoneurons, as they expressed phasic membrane potential oscillations coordinated to the locomotor pattern; the remaining 21 motoneurons did not express any coordination during locomotorlike activity (Fig. 5C). These observations suggest that the absence of extracellularly recorded motor bursts when only the lumbosacral cord was pharmacologically activated was due to a subthreshold activation of thoracic motoneurons. Interestingly, the proportion of locomotor-driven motoneurons is not uniform along the thoracic cord, being found in a more caudal location than nonlocomotor-driven motoneurons (T8T10: 81\%, T6-T7: 64\%, T3-T5: 50\%, $p<$ $0.0001, \chi^{2}$, Fig. 5D).

\section{Characterization of the locomotor}

synaptic drive in thoracic motoneurons To determine the nature of the synaptic drive received by locomotor-driven motoneurons ( $n=6$ from six different preparations), the lumbosacral cord was superfused with NMA/5-HT to induce locomotor episodes, during which the spinal cord was partitioned with a Vaseline wall at the T12/T13 level to selectively bath-apply receptor antagonists to the thoracic level (Fig. 6). Figure $6 A 1$ presents a T7 motoneuron recorded over the course of a locomotor episode. This slow time scale shows a slow 
A1 Locomotor-driven $\mathrm{Mn}$

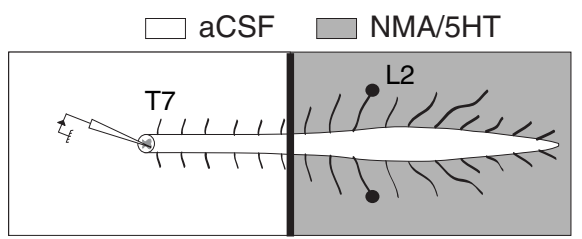

A2

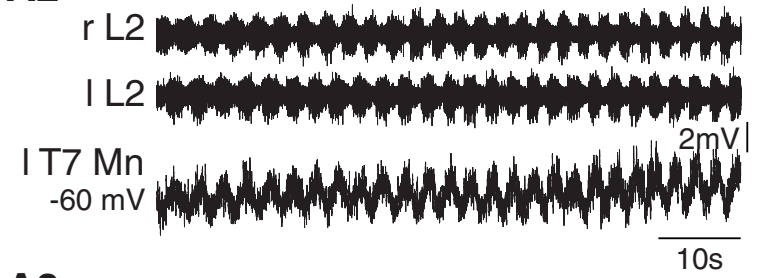

A3

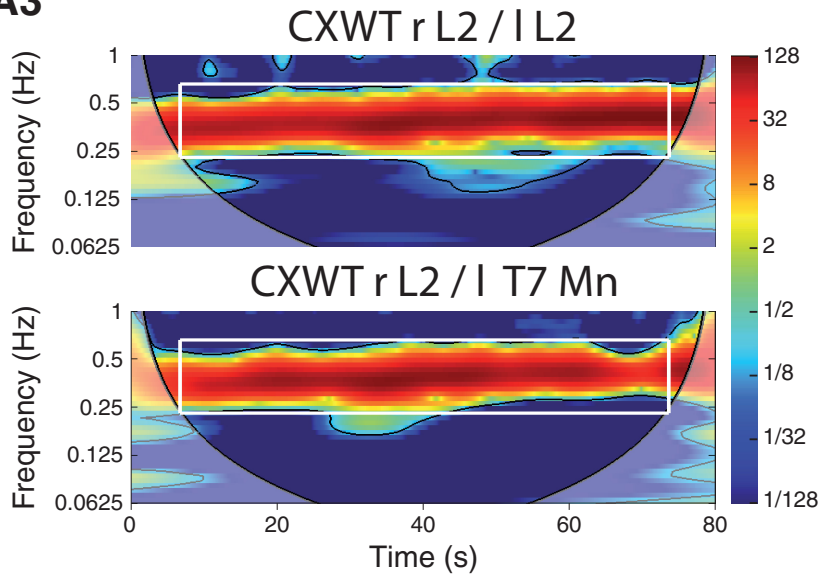

C

$M n$ in phase with ipsilateral L2 bursts

$\mathrm{Mn}$ in phase with contralateral L2 bursts

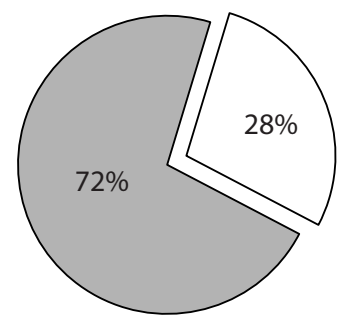

B1 Non locomotor-driven $\mathrm{Mn}$

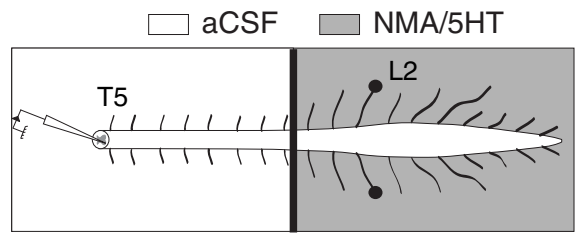

B2

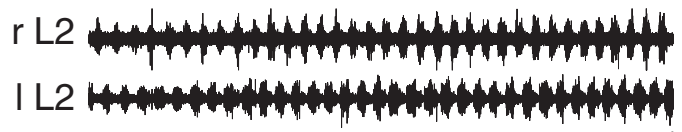

I T5 Mn 2mV|

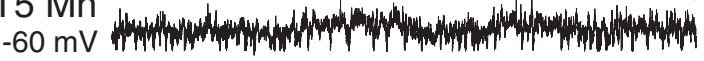

B3

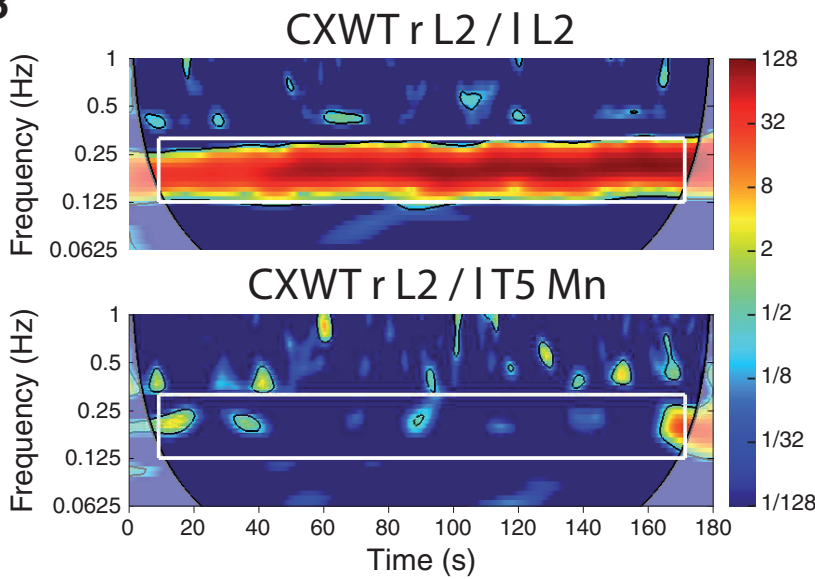

D Locomotor driven Non locomotor driven

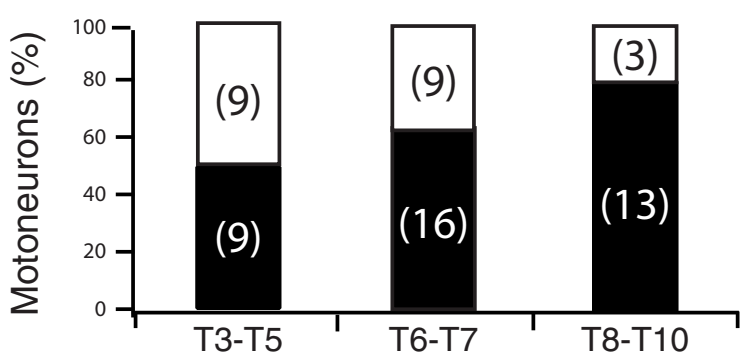

Figure 5. Restricted pharmacological activation of lumbar locomotor networks triggers membrane potential oscillations in thoracic locomotor-driven motoneurons. A1, B1, Schematic of the experimental procedure. A Vaseline wall was built at the T12 level so that the lumbar segments could be activated separately from the thoracic cord. Extracellular recordings were performed from the left and right L2 ventral roots and intracellular recordings from motoneurons were performed at different thoracic levels. The NMA/5-HT mixture was applied to the lumbar cord to induce fictive locomotion. Shown is the activity of an intracellularly recorded motoneuron that exhibited locomotor-timed membrane potential oscillations in this experimental condition (A2, locomotor-driven motoneurons) and of another motoneuron that did not exhibit locomotor-timed membrane potential oscillations in this experimental condition (B2, nonlocomotor-driven motoneurons). Mn, Motoneurons. A3, Mixed cross-coherence maps (CXWT) highlighting the correlation between the activity recorded from L2 ventral roots (top) and between the motoneuron membrane potential oscillations and the right L2 ventral root (bottom). B3, Same representation as in $A 3$. Note that in this case the motoneuron membrane potential fluctuations are not correlated to the lumbar activity. C, The percentage of locomotor-driven motoneurons showing a synaptic drive in phase with the ipsilateral (gray) or contralateral (white) L2 locomotor bursts. D, Cumulative histograms of the percentages of locomotor-driven (black) and nonlocomotor-driven motoneurons in the upper (T3-T5), intermediate (T6-T7), and lower (T8-T10) thoracic segments. Numbers in brackets indicate the number of motoneurons. r, Right; I, left; T, thoracic; L, lumbar.

depolarization of the motoneuron membrane potential of $6 \mathrm{mV}$ during the establishment of the locomotor activity. An expanded view of the sequence (Fig. 6B1) revealed locomotor-related membrane potential oscillations ( $5.9 \pm 0.23 \mathrm{mV}, n=30$ cycles) on top of the slow depolarization. Following the bath application of DNQX (5 $\mu \mathrm{M})$, an AMPA/kainate receptor antagonist, to the thoracic compartment, both the slow depolarization and the am- plitude of locomotor-related oscillations were decreased by $13 \%$ $(5.2 \mathrm{mV})$ and $59 \%(2.4 \pm 0.08 \mathrm{mV}, n=29$ cycles $)$, respectively (Fig. $6 A 2, B 2)$. The subsequent addition of AP5 $(5 \mu \mathrm{M})$, an NMDA receptor antagonist, to the DNQX-containing saline further decreased the amplitude of the slow depolarization $(1.9 \mathrm{mV}, 68 \%$ decrease from the control depolarization) and phasic drive (1.8 \pm $0.07 \mathrm{mV}, 69 \%$ decrease from the control amplitude, $n=29 \mathrm{cy}$ - 
A1

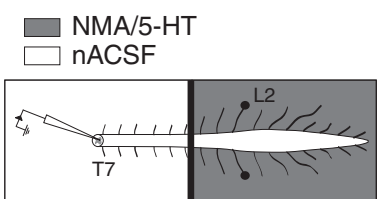

IT7 Mn $-70 \mathrm{mV}$

B1

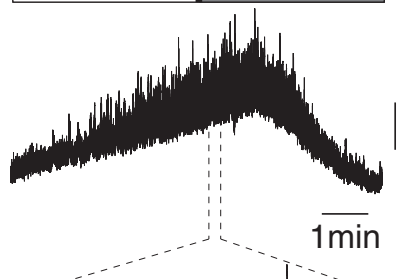

IT7 Mn

rL2

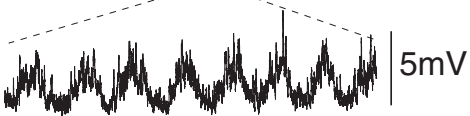

IL2

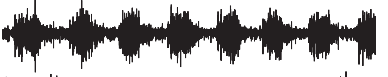

2

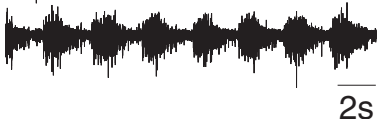

IT7 Mn

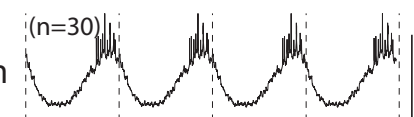

IL2

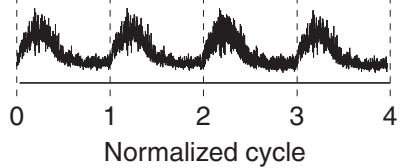

C1
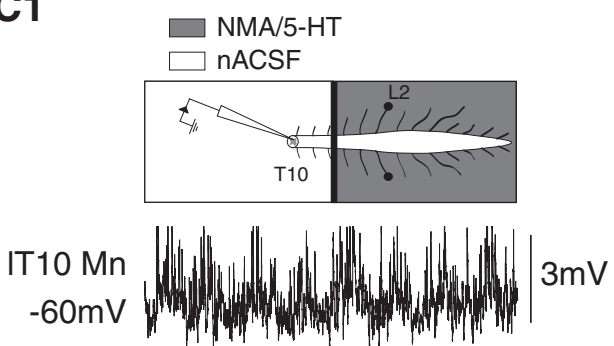

rL2

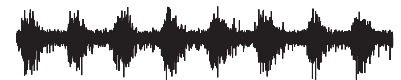

IL2

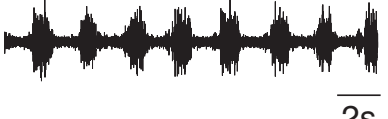

IT10 Mn

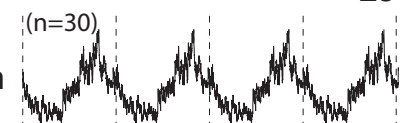

$3 m V$

$5 \mathrm{mV}$

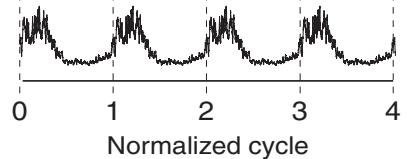

A2

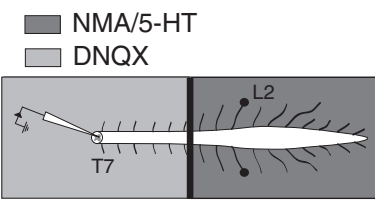

A3

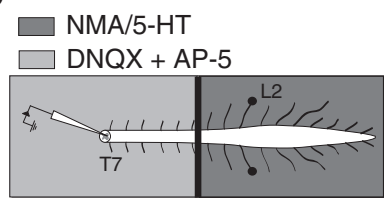

B2
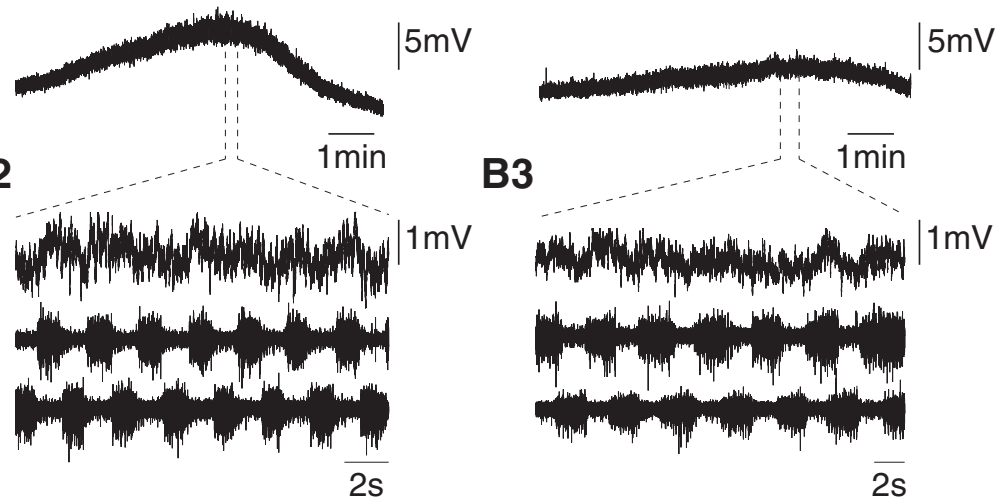

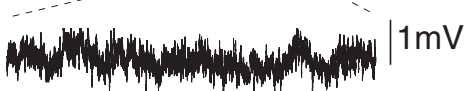
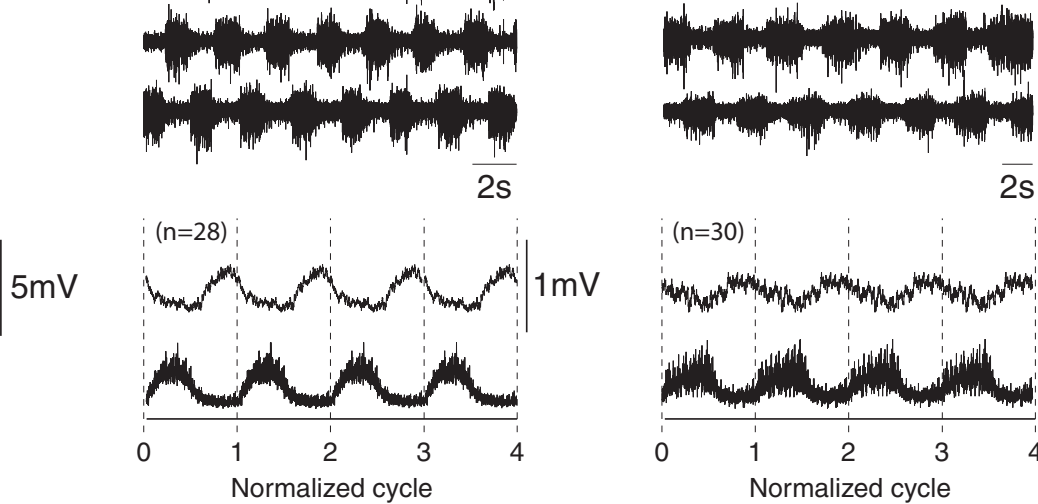

$1 \mathrm{mV}$

C2
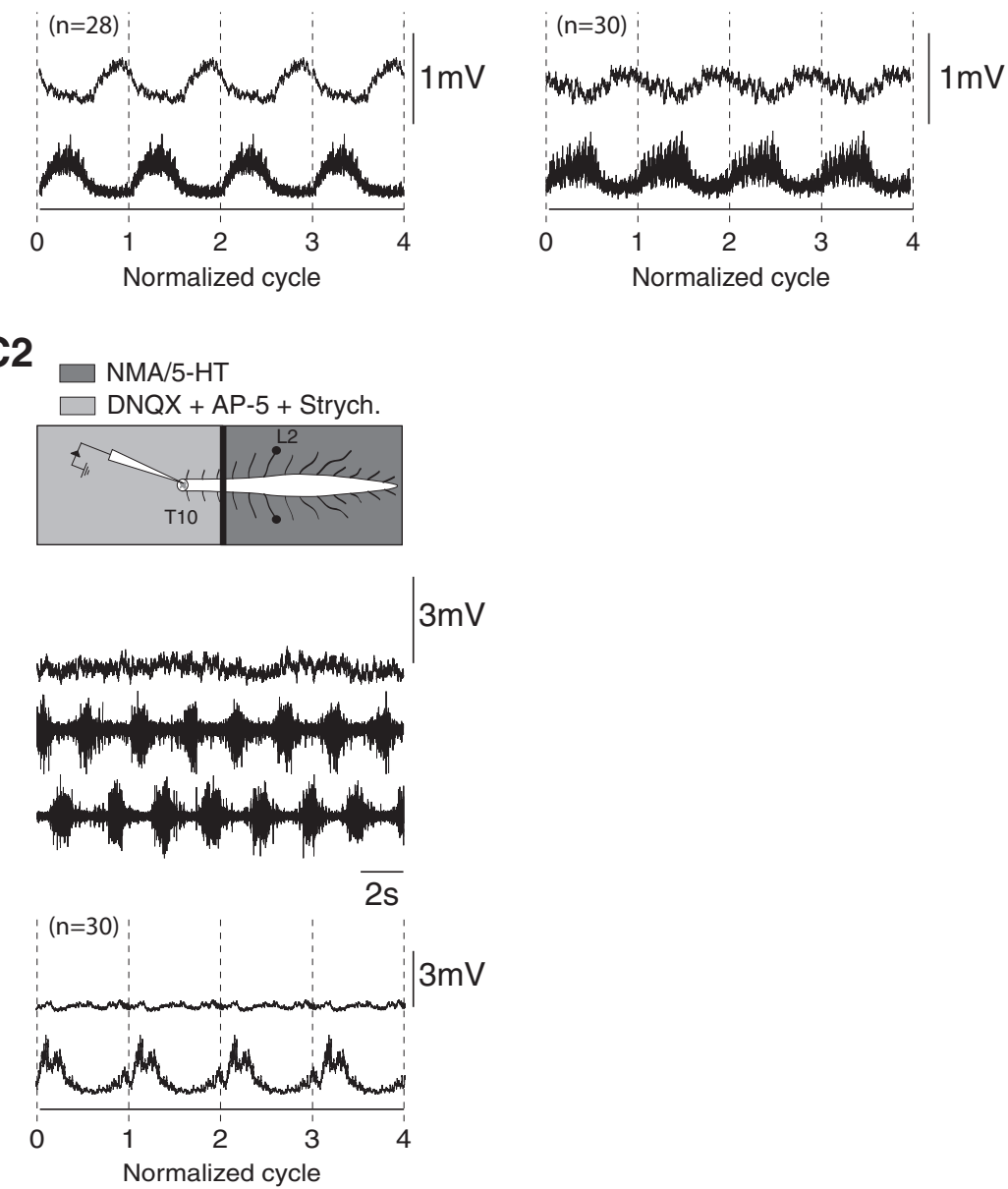

$3 m V$

Figure 6. Characterization of the synaptic drive received by locomotor-driven thoracic motoneurons. $\boldsymbol{A}$, Time courses of the overall membrane potential depolarization recorded from a T7 motoneuron from the onset to the end of a locomotor episode induced by restricted applications of NMA/5-HT compared with the lumbar cord under control conditions (A1), and during thoracic bath application of DNQX (5 $\mu \mathrm{m})$ alone (A2) or combined with AP5 (5 $\mu \mathrm{m} ; \boldsymbol{A 3})$. Note the decreased amplitude of the slow depolarization in the presence of DNQX and DNQX/AP5. B, Sequences of locomotor-like activity extracted from the episodes presented in $A$, which show that the membrane potential oscillations are phase-locked to the locomotor activity. The bottom panels illustrate the mean cycle (repeated 4 times) obtained using the left $L 2$ at the thoracic level under control conditions as the reference, or in the presence of DNQX or DNQX/AP5. C, Representative traces of a thoracic motoneuron (T10) recorded during NMA/5-HT-induced locomotion under control conditions (C1) and in the presence of strychnine (2 $\mu \mathrm{M})$, DNQX (5 $\mu \mathrm{M})$, and AP5 (5 $\mu \mathrm{m}$; C2) applied to the thoracic segments. r, Right; I, left; T, thoracic; L, lumbar. 
cles; Fig. 6A3,B3). We also found that thoracic motoneurons received glycinergic inputs during locomotor-like activity. In the T10 motoneuron presented in Figure 6C1, the phasic membrane potential oscillations were abolished when strychnine $(2 \mu \mathrm{M})$ was added to the saline solution containing DNQX-AP5 that was superfused over the thoracic compartment (Fig. 6C2). Altogether, these experiments indicate that the synaptic drive sustaining the phasic activity of locomotor-driven motoneurons at the thoracic level is mediated through the activation of NMDA and non-NMDA glutamatergic receptors and glycinergic receptors.

\section{The lumbar locomotor network sends a monosynaptic drive to thoracic motoneurons}

Finally, we tested whether the locomotor synaptic drive received by the locomotor-driven thoracic motoneurons directly originated from the lumbar locomotor network. Because aCSF solutions containing a high concentration of cations are known to depress polysynaptic transmission (Berry and Pentreath, 1976; Jahr and Yoshioka, 1986; Cazalets et al., 1995), we tested the effects of the superfusion of a high-cation-containing aCSF to the thoracic cord on intracellularly recorded locomotor-driven thoracic motoneurons ( $n=5$ from five different preparations) following the induction of fictive locomotion by the selective activation of the lumbosacral segments with NMA/5-HT. Figure 7 shows the locomotor synaptic drive of a T5 motoneuron under the control condition (Fig. 7A) and in the presence of the highcation-containing aCSF (Fig. $7 B$ ). Although the synaptic drive received by the motoneuron was depressed $(4.95 \pm 0.15 \mathrm{mV}$ in control condition, $2.49 \pm 0.04 \mathrm{mV}$ in the presence of the highcation solution), it was still possible to discriminate locomotorrelated synaptic inputs when thoracic relays were depressed (Fig. $7 C)$. On average, the amplitude of the locomotor drive was decreased by $43.2 \pm 21.5 \%$ ( $n=5$ motoneurons $)$ by the highcation-containing solution compared with the control condition. This observation thus provides evidence that part of the locomotor synaptic drive sent by the lumbar central pattern generator (CPG) to the thoracic locomotor-driven motoneurons is monosynaptic.

\section{Discussion}

One of the main results of the study, which is summarized in the diagram in Figure 8, is that the lumbar CPG for locomotion makes an important contribution to the emergence of locomotor-like activities at the thoracic level. We have shown that a subset of the thoracic motoneurons, referred to as locomotor-driven motoneurons, express locomotor-related membrane potential oscillations. The membrane potential oscillations in these later motoneurons include an excitatory and inhibitory phase of glutamatergic and glycinergic origin, respectively. The oscillations are thus biphasic. Importantly, we showed for the first time that the lumbar locomotor network itself directly impinges onto the thoracic motoneurons and contributes to the drive of their membrane potential oscillations.

\section{Caudorostral organization of axial thoracic bursts during fictive locomotion}

Although the cervical, lumbar, and sacrococcygeal networks that respectively control the forelimbs, hindlimbs, and tail locomotor movements can be independently activated in the isolated neonatal rat spinal cord (Cazalets et al., 1995; Lev-Tov et al., 2000; Ballion et al., 2001; Gabbay et al., 2002), these networks produce a coordinated activity when simultaneously stimulated (Kremer and Lev-Tov, 1997; Cazalets and Bertrand, 2000a, 2000b; Gabbay et al., 2002; Juvin et al., 2005, 2012). Here, we focused on the
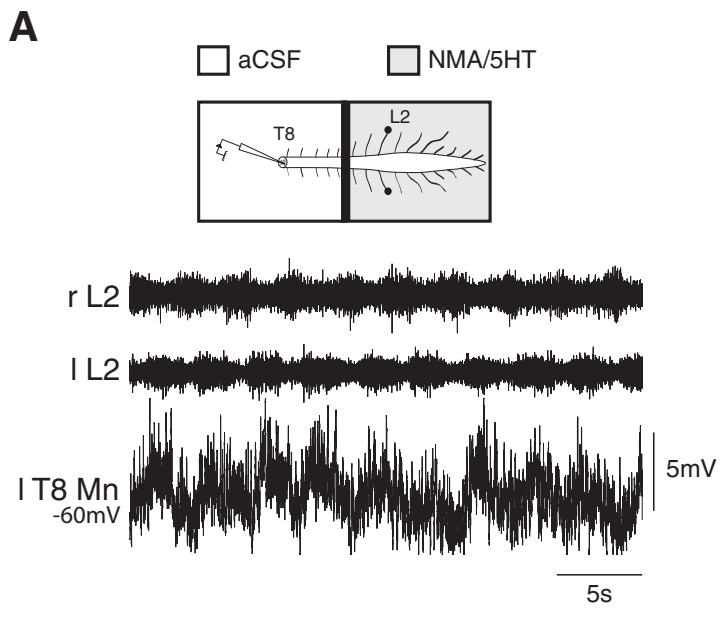

B high Cations $\square$ NMA/5HT
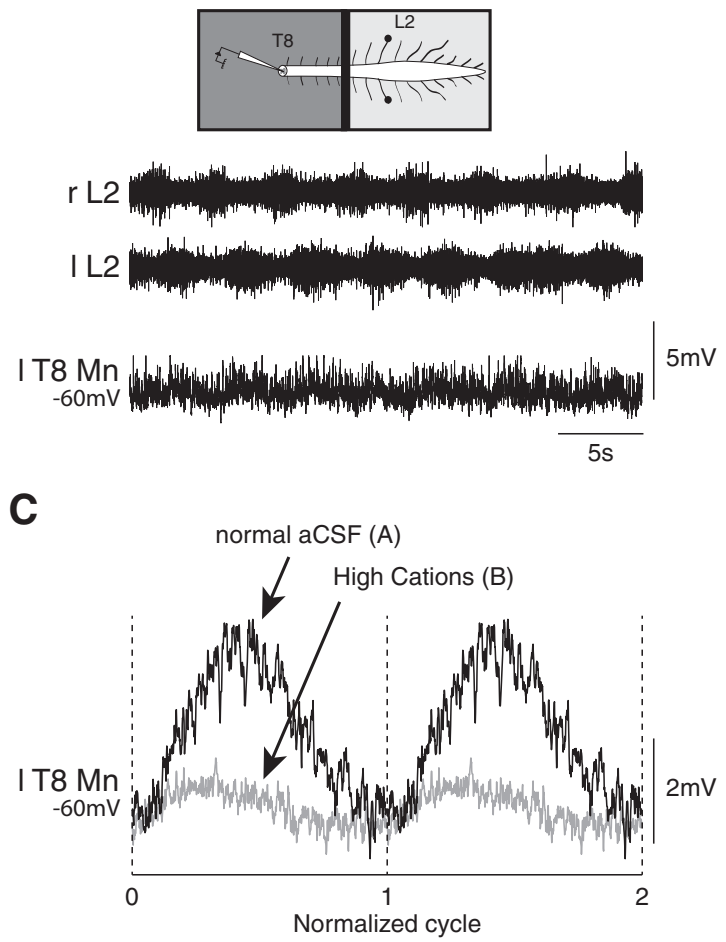

Figure 7. Monosynaptic contribution of the lumbar locomotor network to the synaptic driving of thoracic motoneurons. $A$, Membrane potential oscillations recorded from a T8 motoneuron during NMA/5-HT-induced locomotor-like activity in the lumbar spinal cord. $\boldsymbol{B}$, Decreases in amplitude of the locomotor synaptic drive is still observed in the same motoneuron when a solution containing a high concentration of cations is applied to the thoracic segment to depress the polysynaptic pathways. $C$, The mean synaptic drive computed from the recordings is presented in $\boldsymbol{A}$ and $\boldsymbol{B}$ in normal aCSF (black trace) and in high-cation-containing aCSF (gray trace). r, Right; I, left; $T$, thoracic; L, lumbar.

thoracic networks involved in the control of axial back muscles. Using simultaneous extracellular ventral root recordings from various spinal segments, we confirmed that the thoracic segments can be pharmacologically activated, expressing a bursting activity with a 1:1 phase relationship with the lumbar fictive locomotor output (Falgairolle and Cazalets, 2007). Using continuous wavelet transform analyses, a set of objective mathematical analytical tools that were validated in the field (Fig. 1) (Torrence and Compo, 1998; Grinsted et al., 2004; Mor and Lev-Tov, 2007; Hägglund et al., 2013; Talpalar et al., 2013), we also confirmed 


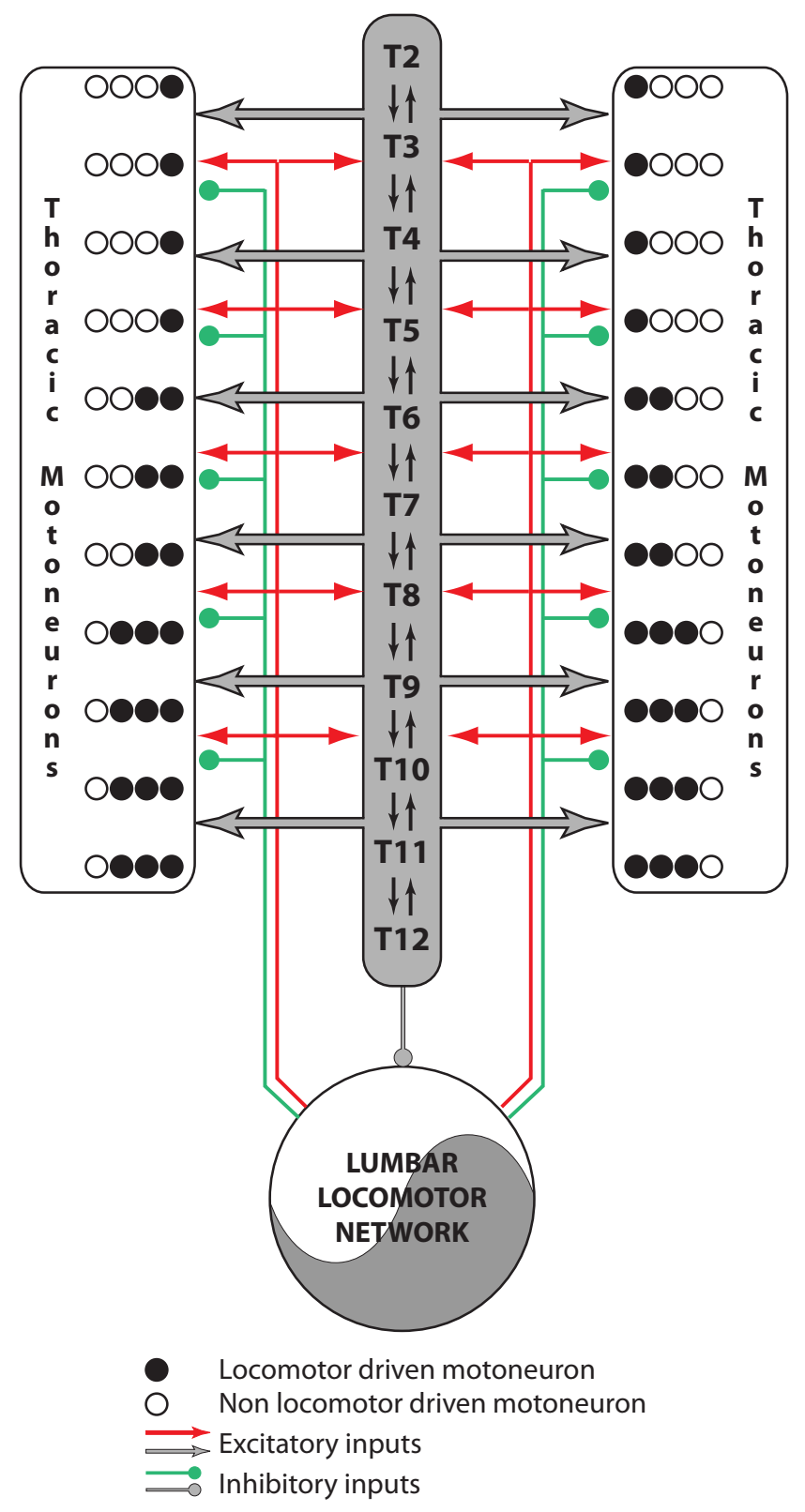

Figure 8. Schematic diagram summarizing the relationships between the lumbar locomotor network and the thoracic circuitry. The lumbar locomotor network drives thoracic activity while acting at both the premotoneuronal (dark gray) and motoneuronal levels through short and long propriospinal pathways. The descending arrow indicates that the thoracic networks can modulate the period of the activity generated by the lumbar locomotor network.

that the thoracic locomotor bursts were organized as ascending traveling waves along the thoracic cord during fictive locomotion. This ascending organization of the thoracic axial bursts, which matched the bending of the body axis during actual locomotor cycles in rat pups, contrasts with the rostrocaudal direction of the traveling wave during forward locomotion in swimming vertebrates (Wallén and Williams, 1984; Tunstall and Roberts, 1991; Matsushima and Grillner, 1992; Masino and Fetcho, 2005; Gabriel et al., 2008). Consequently, it appears that the wave propagation of locomotor bursts along the axial system is one basic locomotor mechanism in vertebrates that was adapted during evolution to sustain the development of limb-based propulsion modes (Delvolvé et al., 1997).
Lumbar locomotor network control of thoracic locomotor activities

Although the thoracic networks have endogenous rhythmogenic capacities, the lumbar networks impose their own rhythmicity on the thoracic circuits during induced locomotor-like activity. Our data further suggest that the lumbosacral region exerts a tonic inhibitory influence over the thoracic segments, as nonlocomotor bursting activity could be observed in the thoracic ventral roots only when the thoracic segments are physically or pharmacologically isolated from the lumbosacral spinal cord (Fig. 2; Cowley and Schmidt, 1997; Kremer and Lev-Tov, 1997; Falgairolle and Cazalets, 2007). We have recently demonstrated that coordination processes and phase relationships between the various spinal levels depends on the neurochemical compounds used to elicit fictive locomotion (Beliez et al., 2014). Although the NMA/5-HT mixture used in the present work is effective in triggering robust locomotor patterns throughout the entire thoracolumbar cord (Beliez et al., 2014), it appears to be less capable of eliciting rhythmical activities in isolated thoracic segments, as is also the case at the sacrococcygeal level (Kremer and Lev-Tov, 1997; Cazalets and Bertrand, 2000a; Lev-Tov et al., 2000; Gabbay et al., 2002). In this context, further work will be needed to determine whether other neuromodulators are more effective in revealing the rhythmogenic capacities of the isolated thoracic networks. For instance, it was established that noradrenaline was more effective than 5 -HT in triggering robust sacrococcygeal rhythmical activities coordinating the tail movements when these segments were isolated from the lumbar cord (Gabbay et al., 2002).

The expression of thoracic locomotor activity thus involved the ascending propriospinal pathways arising from lumbar segments (Riddell et al., 1994; Reed et al., 2006, 2009; Brockett et al., 2013; Reed and Magnuson, 2013). In agreement with previous observations made in the lamprey spinal networks (Hagevik and McClellan, 1999; Miller and Sigvardt, 2000), long ascending pathways were sufficient for maintaining a 1:1 coordination between the locomotor activities of the rostral thoracic and lumbar cord segments when the synaptic transmission was blocked in interposed segments in the neonatal rat spinal cord (Fig. 3). Also, similar with the lamprey, segmentally relayed information contributed to setting the timing of thoracic motor outputs in the rat spinal cord (Riddell et al., 1994; Hagevik and McClellan, 1999; Miller and Sigvardt, 2000; Cazalets, 2005; Falgairolle and Cazalets, 2007). These observations further emphasize the importance of these two types of pathways (long and segmental) to the coordination of spinal networks that have indeed been previously shown to be involved in cervical and lumbar locomotor network interactions (Juvin et al., 2005, 2012). The functional implication of thoracic propriospinal pathways for conveying descending supraspinal locomotor commands has been demonstrated electrophysiologically (Courtine et al., 2008; Cowley et al., 2008; Zaporozhets et al., 2011) and they could also serve in lumbothoracic connectivity since they have been proposed to be bidirectional and segmentally relayed (Cowley et al., 2008; Zaporozhets et al., 2011). Furthermore, recent studies using rabies virus-based methodology have anatomically identified thoracic propriospinal neurons that are monosynaptically connected to hindlimb and axial motoneurons and which may contribute to coordinating trunk and hindlimb muscle activity (Ni et al., 2014; Pivetta et al., 2014; Goetz et al., 2015).

We found that the locomotor period was decreased when the lumbosacral segments were activated independently of the thoracic networks (Fig. 3). This result suggests that thoracic neuron 
excitability affects and modulates the lumbar CPG motor output. Likewise, it was shown in the turtle that midthoracic segments contribute to setting the frequency of the scratching motor pattern expressed in ex vivo spinal cord preparations, although these segments are not critical to the expression of hindlimb scratching (Guzulaitis et al., 2014). Our observation is also in the same vein as the recent observation that increasing the excitability of the thoracic segments can facilitate the expression of treadmill locomotion following staggered bilateral thoracic hemisections or a complete spinal cord transection in adult rats (Cowley et al., 2015). The relationships between the thoracic and lumbar networks thus appear to be reciprocal in our preparation. Overall, however, our data do not challenge the asymmetrical nature of the relationship between the lumbar locomotor network and the cervical, thoracic, and sacral motor networks; the former imposes more of its own rhythm and/or contributes to setting the temporal bursting patterns of the latter three (Kremer and Lev-Tov, 1997; Cazalets and Bertrand, 2000a, 2000b; Gabbay et al., 2002; Juvin et al., 2005).

\section{The locomotor drive received by thoracic motoneurons}

Intracellular recordings from thoracic motoneurons revealed two different populations along the thoracic cord (Figs. 4, 5). The first population includes locomotor-driven motoneurons that express phasic membrane potential oscillations during fictive locomotion, while the second population regroups nonlocomotordriven motoneurons that did not exhibit any locomotor-related synaptic drive. It is likely that locomotor-driven motoneurons may correspond to the ventromedial motoneurons that innervate the back and abdominal muscles that have been shown to be rhythmically active during locomotion (Carlson et al., 1979, 1988; Thorstensson et al., 1982; Smith and Hollyday, 1983; Zomlefer et al., 1984; Delvolvé et al., 1997; Gramsbergen et al., 1999; de Sèze et al., 2008; Hu et al., 2012). However, we cannot rule out the possibility that in our experimental conditions, the number of locomotor-driven motoneurons may have been underestimated. First, the fact that their proportion decreased caudorostrally along the spinal cord (Fig. 5) raises the possibility that some of them, especially in the rostral segments, could be recruited when the cervical locomotor network is active (Ballion et al., 2001). Second, nonlocomotor-driven motoneurons are possibly not part of the rhythmic network, or are inhibited when the lumbar locomotor network is active. Third, the recruitment of segmental thoracic motoneurons may not be uniform not only at the segmental level but also along the cord, especially under our pharmacological conditions. For instance, the recruitment of specific locomotor interneurons and axial motoneurons during swimming in larval Xenopus and zebrafish has been shown to result from complex interactions between endogenous motoneuron membrane properties, passive motoneuronal filtering of synaptic inputs, and the strength and frequency of the incoming synaptic inputs responsible for the oscillatory drive (Tunstall and Roberts, 1994; Gabriel et al., 2010; Ausborn et al., 2012; Menelaou and McLean, 2012; Ampatzis et al., 2013). Interestingly, it was shown in adult zebrafish that the recruitment of the four axial motoneuron classes reported at this developmental stage was ultimately a function of the muscle fiber types they innervate, and corresponds to the recruitment order of slow, intermediate, and fast muscles during episodes of swimming at increasing speeds (Ampatzis et al., 2013). Further work will be needed to determine whether the same type of control mechanism operates in the rat spinal cord, especially at the thoracic level. In particular, eliciting episodes of fictive locomotion at various frequencies, for instance through brainstem or spinal cord electrical stimulations while recording from thoracic axial motoneurons, awaits assessment in the future.

The locomotor drive recorded from thoracic motoneurons included an excitatory and an inhibitory component, making it biphasic (Fig. 6). This locomotor drive is similar to the one that has been described in lumbar motoneurons (Cazalets et al., 1996). Interestingly, we showed that the lumbar locomotor network connects at least partly monosynaptically to thoracic motoneurons (Fig. 7). The reduced amplitude of the membrane potential oscillations when the polysynaptic transmission was blocked in the thoracic cord indicates that the thoracic circuitry actually contributed to the synaptic driving force. To our knowledge, we provide here the first evidence that the lumbar locomotor network can contribute to the timing of motor output produced in distant segments through a dual access to premotoneuronal and motoneuronal elements. Further work will be required to evaluate whether the lumbar locomotor network can also access the sacral and cervical motoneurons.

\section{Conclusion}

Although the trunk plays a central role in posture and limbed locomotion (Carlson et al., 1988; de Sèze et al., 2008; Schmidt and Fischer, 2010), the thoracic networks controlling the trunk muscles have until now gone largely unstudied in mammals. We have gone one step further in the understanding of the functional coupling between the lumbar locomotor network and the axial thoracic networks. This work is part of a global, functional approach of the spinal networks (Juvin et al., 2005; Falgairolle et al., 2006; Falgairolle and Cazalets, 2007; Juvin et al., 2012), the understanding of which will probably be helpful in designing innovative, therapeutic strategies for restoring motor activities following spinal cord injuries (Bjerkefors et al., 2009).

\section{References}

Ampatzis K, Song J, Ausborn J, El Manira A (2013) Pattern of innervation and recruitment of different classes of motoneurons in adult zebrafish. J Neurosci 33:10875-10886. CrossRef Medline

Ausborn J, Mahmood R, El Manira A (2012) Decoding the rules of recruitment of excitatory interneurons in the adult zebrafish locomotor network. Proc Natl Acad Sci U S A 109:E3631-E3639. CrossRef Medline

Ballion B, Morin D, Viala D (2001) Forelimb locomotor generators and quadrupedal locomotion in the neonatal rat. Eur J Neurosci 14:17271738. CrossRef Medline

Beliez L, Barrière G, Bertrand SS, Cazalets JR (2014) Multiple monoaminergic modulation of posturo-locomotor network activity in the newborn rat spinal cord. Front Neural Circuits 8:99. CrossRef Medline

Berens P (2009) CircStat: a Matlab toolbox for circular statistics. J Statistical Software 31:1-21.

Berry MS, Pentreath VW (1976) Criteria for distinguishing between monosynaptic and polysynaptic transmission. Brain Res 105:1-20. CrossRef Medline

Bjerkefors A, Carpenter MG, Cresswell AG, Thorstensson A (2009) Trunk muscle activation in a person with clinically complete thoracic spinal cord injury. J Rehabil Med 41:390-392. CrossRef Medline

Brockett EG, Seenan PG, Bannatyne BA, Maxwell DJ (2013) Ascending and descending propriospinal pathways between lumbar and cervical segments in the rat: evidence for a substantial ascending excitatory pathway. Neuroscience 240:83-97. CrossRef Medline

Carlson H, Halbertsma J, Zomlefer M (1979) Control of the trunk during walking in the cat. Acta Physiol Scand 105:251-253. CrossRef Medline

Carlson H, Thorstensson A, Nilsson J (1988) Lumbar back muscle activity during locmotion: effects of voluntary modifications of normal trunk movements. Acta Physiol Scand 133:343-353. Medline

Cazalets JR (2005) Metachronal propagation of motoneurone burst activation in isolated spinal cord of newborn rat. J Physiol 568:583-597. CrossRef Medline 
Cazalets JR, Bertrand S (2000a) Coupling between lumbar and sacral motor networks in the neonatal rat spinal cord. Eur J Neurosci 12:2993-3002. CrossRef Medline

Cazalets JR, Bertrand S (2000b) Ubiquity of motor networks in the spinal cord of vertebrates. Brain Res Bull 53:627-634. CrossRef Medline

Cazalets JR, Sqalli-Houssaini Y, Clarac F (1992) Activation of the central pattern generators for locomotion by serotonin and excitatory amino acids in neonatal rat. J Physiol 455:187-204. CrossRef Medline

Cazalets JR, Borde M, Clarac F (1995) Localization and organization of the central pattern generator for hindlimb locomotion in newborn rat. J Neurosci 15:4943-4951. Medline

Cazalets JR, Borde M, Clarac F (1996) The synaptic drive from the spinal locomotor network to motoneurons in the newborn rat. J Neurosci 16 : 298-306. Medline

Ceccato J-C, Sèze M de, Azevedo C, Cazalets J-R (2009) Comparison of trunk activity during gait initiation and walking in humans. PLoS One 4:e8193. CrossRef Medline

Cohen $\mathrm{AH}$ (1987) Intersegmental coordinating system of the lamprey central pattern generator for locomotion. J Comp Physiol A 160:181-183.

Courtine G, Song B, Roy RR, Zhong H, Herrmann JE, Ao Y, Qi J, Edgerton VR, Sofroniew MV (2008) Recovery of supraspinal control of stepping via indirect propriospinal relay connections after spinal cord injury. Nat Med 14:69-74. CrossRef Medline

Cowley KC, Schmidt BJ (1997) Regional distribution of the locomotor pattern-generating network in the neonatal rat spinal cord. J Neurophysiol 77:247-259. Medline

Cowley KC, Zaporozhets E, Schmidt BJ (2008) Propriospinal neurons are sufficient for bulbospinal transmission of the locomotor command signal in the neonatal rat spinal cord. J Physiol 586:1623-1635. CrossRef Medline

Cowley KC, MacNeil BJ, Chopek JW, Sutherland S, Schmidt BJ (2015) Neurochemical excitation of thoracic propriospinal neurons improves hindlimb stepping in adult rats with spinal cord lesions. Exp Neurol 264: 174-187. CrossRef Medline

Deliagina TG, Beloozerova IN, Zelenin PV, Orlovsky GN (2008) Spinal and supraspinal postural networks. Brain Res Rev 57:212-221. CrossRef Medline

Delvolvé I, Bem T, Cabelguen JM (1997) Epaxial and limb muscle activity during swimming and terrestrial stepping in the adult newt, Pleurodeles waltl. J Neurophysiol 78:638-650. Medline

de Sèze M, Falgairolle M, Viel S, Assaiante C, Cazalets JR (2008) Sequential activation of axial muscles during different forms of rhythmic behavior in man. Exp Brain Res 185:237-247. CrossRef Medline

Falgairolle M, Cazalets JR (2007) Metachronal coupling between spinal neuronal networks during locomotor activity in newborn rat. J Physiol 580:87-102. CrossRef Medline

Falgairolle M, de Seze M, Juvin L, Morin D, Cazalets JR (2006) Coordinated network functioning in the spinal cord: an evolutionary perspective. J Physiol Paris 100:304-316. CrossRef Medline

Falgairolle M, Ceccato JC, de Seze M, Herbin M, Cazalets JR (2013) Metachronal propagation of motor activity. Front Biosci (Landmark Ed) 18: 820-837. Medline

Gabbay H, Delvolvé I, Lev-Tov A (2002) Pattern generation in caudallumbar and sacrococcygeal segments of the neonatal rat spinal cord. J Neurophysiol 88:732-739. Medline

Gabriel JP, Mahmood R, Walter AM, Kyriakatos A, Hauptmann G, Calabrese RL, El Manira A (2008) Locomotor pattern in the adult zebrafish spinal cord in vitro. J Neurophysiol 99:37-48. CrossRef Medline

Gabriel JP, Ausborn J, Ampatzis K, Mahmood R, Eklöf-Ljunggren E, Manira El A (2010) Principles governing recruitment of motoneurons during swimming in zebrafish. Nat Neurosci 14:93-99. Medline

Goetz C, Pivetta C, Arber S (2015) Distinct limb and trunk premotor circuits establish laterality in the spinal cord. Neuron 85:131-144. CrossRef Medline

Gramsbergen A, Geisler HC, Taekema H, van Eykern LA (1999) The activation of back muscles during locomotion in the developing rat. Brain Res Dev Brain Res 112:217-228. CrossRef Medline

Grillner S, Wallen P (2002) Cellular bases of a vertebrate locomotor systemsteering, intersegmental and segmental co-ordination and sensory control. Brain Res Brain Res Rev 40:92-106. CrossRef Medline

Grillner S, Deliagina T, Ekeberg O, el Manira A, Hill RH, Lansner A, Orlovsky GN, Wallén P (1995) Neural networks that co-ordinate locomotion and body orientation in lamprey. Trends Neurosci 18:270-279. CrossRef Medline

Grinsted A, Moore JC, Jevrejeva S (2004) Application of the cross wavelet transform and wavelet coherence to geophysical time series. Nonlin Process Geophys 11:561566.

Guzulaitis R, Alaburda A, Hounsgaard J (2014) Dense distributed processing in a hindlimb scratch motor network. J Neurosci 34:10756-10764. CrossRef Medline

Hagevik A, McClellan AD (1999) Coordination of locomotor activity in the lamprey: role of descending drive to oscillators along the spinal cord. Exp Brain Res 128:481-490. CrossRef Medline

Hägglund M, Dougherty KJ, Borgius L, Itohara S, Iwasato T, Kiehn O (2013) Optogenetic dissection reveals multiple rhythmogenic modules underlying locomotion. Proc Natl Acad Sci U S A 110:11589-11594. CrossRef Medline

Hu H, Meijer OG, Hodges PW, Bruijn SM, Strijers RL, Nanayakkara PW, van Royen BJ, Wu WH, Xia C, van Dieën JH (2012) Control of the lateral abdominal muscles during walking. Hum Mov Sci 31:880-896. CrossRef Medline

Jahr CE, Yoshioka K (1986) Ia afferent excitation of motoneurones in the in vitro new-born rat spinal cord is selectively antagonized by kynurenate. J Physiol 370:515-530. CrossRef Medline

Juvin L, Simmers J, Morin D (2005) Propriospinal circuitry underlying interlimb coordination in mammalian quadrupedal locomotion. J Neurosci 25:6025-6035. CrossRef Medline

Juvin L, Le Gal JP, Simmers J, Morin D (2012) Cervicolumbar coordination in mammalian quadrupedal locomotion: role of spinal thoracic circuitry and limb sensory inputs. J Neurosci 32:953-965. CrossRef Medline

Koehler WJ, Schomburg ED, Steffens H (1984) Phasic modulation of trunk muscle efferents during fictive spinal locomotion in cats. J Physiol 353: 187-197. CrossRef Medline

Kremer E, Lev-Tov A (1997) Localization of the spinal network associated with generation of hindlimb locomotion in the neonatal rat and organization of its transverse coupling system. J Neurophysiol 77:1155-1170. Medline

Lev-Tov A, Delvolvé I, Kremer E (2000) Sacrocaudal afferents induce rhythmic efferent bursting in isolated spinal cords of neonatal rats. J Neurophysiol 83:888-894. Medline

Masino MA, Fetcho JR (2005) Fictive swimming motor patterns in wild type and mutant larval zebrafish. J Neurophysiol 93:3177-3188. CrossRef Medline

Matsushima T, Grillner S (1992) Neural mechanisms of intersegmental coordination in lamprey: local excitability changes modify the phase coupling along the spinal cord. J Neurophysiol 67:373-388. Medline

Menelaou E, McLean DL (2012) A gradient in endogenous rhythmicity and oscillatory drive matches recruitment order in an axial motor pool. J Neurosci 32:10925-10939. CrossRef Medline

Miller WL, Sigvardt KA (2000) Extent and role of multisegmental coupling in the lamprey spinal locomotor pattern generator. J Neurophysiol 83: 465-476. Medline

Mor Y, Lev-Tov A (2007) Analysis of rhythmic patterns produced by spinal neural networks. J Neurophysiol 98:2807-2817. CrossRef Medline

Morin D, Viala D (2002) Coordinations of locomotor and respiratory rhythms in vitro are critically dependent on hindlimb sensory inputs. J Neurosci 22:4756-4765. Medline

Ni Y, Nawabi H, Liu X, Yang L, Miyamichi K, Tedeschi A, Xu B, Wall NR, Callaway EM, He Z (2014) Characterization of long descending premotor propriospinal neurons in the spinal cord. J Neurosci 34:9404-9417. CrossRef Medline

Pierce ML, Deuchars J, Deuchars SA (2010) Spontaneous rhythmogenic capabilities of sympathetic neuronal assemblies in the rat spinal cord slice. Neuroscience 170:827-838. CrossRef Medline

Pivetta C, Esposito MS, Sigrist M, Arber S (2014) Motor-circuit communication matrix from spinal cord to brainstem neurons revealed by developmental origin. Cell 156:537-548. CrossRef Medline

Reed WR, Magnuson DS (2013) Cervical response among ascending ventrolateral funiculus pathways of the neonatal rat. Brain Res 1491:136146. CrossRef Medline

Reed WR, Shum-Siu A, Onifer SM, Magnuson DS (2006) Inter-enlargement pathways in the ventrolateral funiculus of the adult rat spinal cord. Neuroscience 142:1195-1207. CrossRef Medline

Reed WR, Shum-Siu A, Whelan A, Onifer SM, Magnuson DS (2009) An- 
terograde labeling of ventrolateral funiculus pathways with spinal enlargement connections in the adult rat spinal cord. Brain Res 1302:76-84. CrossRef Medline

Richards CD, Sercombe R (1970) Calcium, magnesium and the electrical activity of guinea-pig olfactory coex in vitro. J Physiol 211:571-584. CrossRef Medline

Riddell JS, Jankowska E, Hammar I, Szabo-Läckberg Z (1994) Ascending tract neurones processing information from group II muscle afferents in sacral segments of the feline spinal cord. J Physiol 475:469-481. CrossRef Medline

Roberts A, Soffe SR, Wolf ES, Yoshida M, Zhao FY (1998) Central circuits controlling locomotion in young frog tadpoles. Ann N Y Acad Sci 860: 19-34. CrossRef Medline

Rossignol S, Dubuc R, Gossard JP (2006) Dynamic sensorimotor interactions in locomotion. Physiol Rev 86:89-154. CrossRef Medline

Schmidt A, Fischer MS (2010) Arboreal locomotion in rats-the challenge of maintaining stability. J Exp Biol 213:3615-3624. CrossRef Medline

Smith CL, Hollyday M (1983) The development and postnatal organization of motor nuclei in the rat thoracic spinal cord. J Comp Neurol 220:16-28. CrossRef Medline

Sqalli-Houssaini Y, Cazalets JR, Clarac F (1993) Oscillatory properties of the central pattern generator for locomotion in neonatal rats. J Neurophysiol 70:803-813. Medline

Talpalar AE, Bouvier J, Borgius L, Fortin G, Pierani A, Kiehn O (2013) Dualmode operation of neuronal networks involved in left-right alternation. Nature 500:85-88. CrossRef Medline
Tartas M, Morin F, Barrière G, Goillandeau M, Lacaille JC, Cazalets JR, Bertrand SS (2010) Noradrenergic modulation of intrinsic and synaptic properties of lumbar motoneurons in the neonatal rat spinal cord. Front Neural Circuits 4:4. Medline

Thorstensson A, Carlson H, Zomlefer MR, Nilsson J (1982) Lumbar back muscle activity in relation to trunk movements during locomotion in man. Acta Physiol Scand 116:13-20. CrossRef Medline

Torrence C, Compo GP (1998) A practical guide to wavelet analysis. Bull Am Meteorol Soc 79:61-78. CrossRef

Tunstall MJ, Roberts A (1991) Longitudinal coordination of motor output during swimming in Xenopus embryos. Proc Biol Sci 244:27-32. CrossRef Medline

Tunstall MJ, Roberts A (1994) A longitudinal gradient of synaptic drive in the spinal cord of Xenopus embryos and its role in co-ordination of swimming. J Physiol 474:393-405. CrossRef Medline

Wallén P, Williams TL (1984) Fictive locomotion in the lamprey spinal cord in vitro compared with swimming in the intact and spinal animal. J Physiol 347:225-239. CrossRef Medline

Zaporozhets E, Cowley KC, Schmidt BJ (2011) Neurochemical excitation of propriospinal neurons facilitates locomotor command signal transmission in the lesioned spinal cord. J Neurophysiol 105:2818-2829. CrossRef Medline

Zomlefer MR, Provencher J, Blanchette G, Rossignol S (1984) Electromyographic study of lumbar back muscles during locomotion in acute high decerebrate and in low spinal cats. Brain Res 290:249-260. CrossRef Medline 